ARTICLE

https://doi.org/10.1038/s41467-019-12504-y

\title{
Viral $N^{6}$-methyladenosine upregulates replication and pathogenesis of human respiratory syncytial virus
}

\author{
Miaoge Xue ${ }^{1}$, Boxuan Simen Zhao ${ }^{2}$, Zijie Zhang (1) ${ }^{2}$, Mijia Lu' ${ }^{1}$ Olivia Harder ${ }^{1}$, Phylip Chen ${ }^{3}$, Zhike Lu²,

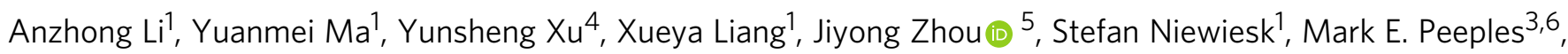 \\ Chuan $\mathrm{He}{ }^{2}{ }^{2,7} \&$ Jianrong $\mathrm{Li}^{1 \star}$
}

$N^{6}$-methyladenosine $\left(\mathrm{m}^{6} \mathrm{~A}\right)$ is the most prevalent internal modification of mRNAs in most eukaryotes. Here we show that RNAs of human respiratory syncytial virus (RSV) are modified by $\mathrm{m}^{6} \mathrm{~A}$ within discreet regions and that these modifications enhance viral replication and pathogenesis. Knockdown of $\mathrm{m}^{6} \mathrm{~A}$ methyltransferases decreases RSV replication and gene expression whereas knockdown of $\mathrm{m}^{6} \mathrm{~A}$ demethylases has the opposite effect. The $\mathrm{G}$ gene transcript contains the most $\mathrm{m}^{6} \mathrm{~A}$ modifications. Recombinant RSV variants expressing $\mathrm{G}$ transcripts that lack particular clusters of $\mathrm{m}^{6} \mathrm{~A}$ display reduced replication in A549 cells, primary well differentiated human airway epithelial cultures, and respiratory tracts of cotton rats. One of the $\mathrm{m}^{6} \mathrm{~A}$-deficient variants is highly attenuated yet retains high immunogenicity in cotton rats. Collectively, our results demonstrate that viral $\mathrm{m}^{6} \mathrm{~A}$ methylation upregulates RSV replication and pathogenesis and identify viral $\mathrm{m}^{6} \mathrm{~A}$ methylation as a target for rational design of live attenuated vaccine candidates for RSV and perhaps other pneumoviruses.

\footnotetext{
${ }^{1}$ Department of Veterinary Biosciences, College of Veterinary Medicine, The Ohio State University, Columbus, OH 43210, USA. ${ }^{2}$ Department of Chemistry, Department of Biochemistry and Molecular Biology, and Institute for Biophysical Dynamics, The University of Chicago, Chicago, IL 60637, USA. ${ }^{3}$ Center for Vaccines and Immunity, The Research Institute at Nationwide Children's Hospital, Columbus, OH 43205, USA. ${ }^{4}$ Institute of Translational Medicine, The First Affiliated Hospital of Wenzhou Medical University, Wenzhou, 325015 Zhejiang, P.R. China. ${ }^{5}$ College of Animal Sciences, Zhejiang University, Hangzhou, 310058 Zhejiang, P. R. China. ${ }^{6}$ Department of Pediatrics, The Ohio State University College of Medicine, Columbus, OH 43210, USA. ${ }^{7}$ Howard Hughes Medical Institute, The University of Chicago, Chicago, IL 60637, USA. *email: li.926@osu.edu
} 
nternal $N^{6}$-methyladenosine $\left(\mathrm{m}^{6} \mathrm{~A}\right)$ is the most prevalent modification in the mRNA of most eukaryotes ${ }^{1,2}$. Although $\mathrm{m}^{6} \mathrm{~A}$ was discovered in the $1970 \mathrm{~s}^{3-6}$, its biological functions remained a mystery for decades. In 2011, $\mathrm{m}^{6} \mathrm{~A}$ demethylases were discovered $^{7,8}$. It is generally believed that $\mathrm{m}^{6} \mathrm{~A}$ methylation is reversible although studies also suggest that a substantial degree of demethylation did not occur in some mRNA exons ${ }^{9}$. Transcriptome-wide mapping of $\mathrm{m}^{6} \mathrm{~A}$ by high-throughput sequencing technology was reported subsequently ${ }^{10-12}$. A series of $\mathrm{m}^{6} \mathrm{~A}$-related enzymes and proteins were also discovered and characterized in mammalian cells. Recent work has found that $\mathrm{m}^{6} \mathrm{~A}$ regulates RNA metabolism, protein translation, gene expression, and embryonic development in organisms ranging from plants to mice ${ }^{13-17}$.

The $\mathrm{m}^{6} \mathrm{~A}$ modification is installed by the $\mathrm{m}^{6} \mathrm{~A}$ methylation "writer" protein, a multicomponent S-adenosyl-L-methionine (SAM)-dependent methyltransferase complex, composed of two subunits, METTL3 (a catalytic enzyme) and METTL14 (an allosteric activator), and facilitated by the Wilms tumor 1 associated protein (WTAP) ${ }^{18,19}$. Interestingly, $\mathrm{m}^{6} \mathrm{~A}$ modification can be selectively removed by two mammalian RNA demethylases, FTO (fat mass and obesity-associated protein) and its homolog, ALKBH5, both of which are termed $\mathrm{m}^{6} \mathrm{~A}$ "eraser" proteins $\mathrm{s}^{7,8}$. The biological functions of $\mathrm{m}^{6} \mathrm{~A}$ are mediated through $\mathrm{m}^{6} \mathrm{~A}$ "reader" proteins that specifically recognize and bind the methylated adenosine on RNA. The recently characterized $\mathrm{m}^{6} \mathrm{~A}$ binding proteins include the YT521-B homology (YTH) domain family of proteins (YTHDF1, YTHDF2, YTHDF3, and YTHDC1) 16,20,21. These $\mathrm{m}^{6} \mathrm{~A}$ binding proteins regulate protein translation and RNA decay 22,23 .

As obligate intracellular parasites, viruses must synthesize their own genetic material and carry out their reproduction while avoiding innate immune surveillance by mimicking their host. Studies from the early 1970s showed that viral RNAs of several DNA viruses, retroviruses, and influenza virus contained internal $\mathrm{m}^{6} \mathrm{~A}$ modifications $\mathrm{s}^{4,24-29}$. Although it is still controversial whether viral $\mathrm{m}^{6} \mathrm{~A}$ positively or negatively regulates $\mathrm{HIV}$ replication $^{30-32}$, it was shown that $\mathrm{m}^{6} \mathrm{~A}$ promotes gene expression of influenza virus ${ }^{33}$ and simian virus $40^{34}$. In the case of Kaposi's sarcoma-associated herpesvirus (KSHV), the impact of $\mathrm{m}^{6} \mathrm{~A}$ machinery on viral gene expression is dependent on the cell type ${ }^{35-37}$. In contrast, $\mathrm{m}^{6} \mathrm{~A}$ negatively regulates the production of hepatitis $\mathrm{C}$ virus $(\mathrm{HCV})$ and Zika virus ${ }^{38}$. However, the mechanism(s) by which $\mathrm{m}^{6} \mathrm{~A}$ methylation regulates the virus life cycle remain poorly understood. In addition, the roles of $\mathrm{m}^{6} \mathrm{~A}$ in viral virulence, pathogenesis, and immunity are not clear.

Non-segmented negative-sense (NNS) RNA viruses encompass a wide range of significant human, animal, and plant pathogens. For many of these agents, there are no effective vaccines or antiviral drugs. The replication and gene expression strategy of NNS RNA viruses is unique. During transcription, the polymerase transcribes the linear array of genes in the viral genome into 5-10 mRNAs that are capped and methylated at the $5^{\prime}$ end and polyadenylated at the $3^{\prime}$ end. During replication, the polymerase initiates at the extreme $3^{\prime}$ end of the genome and ignores the gene junctions to synthesize a full-length complementary antigenome which is encapsidated by $\mathrm{N}$ protein and subsequently serves as template for the synthesis of full-length progeny genomes that are likewise encapsidated by $\mathrm{N}$ protein ${ }^{39,40}$. A good example of NNS RNA viruses is human respiratory syncytial virus (RSV), a member of the Pneumoviridae ${ }^{41}$. RSV is the most important cause of upper and lower respiratory tract infection of infants, young children, and immunocompromised individuals and second only to influenza virus for the elderly ${ }^{42}$. Worldwide it is estimated that RSV causes 3.4 million hospitalizations and between 66,000 and 199,000 deaths in children $<5$ years of age ${ }^{43}$.
Despite major efforts, no vaccine or antiviral drug is yet available for $\mathrm{RSV}^{42}$

Here, we find that the RSV genome, antigenome, and mRNAs are $\mathrm{m}^{6} \mathrm{~A}$ methylated internally at specific sites which positively regulate RSV replication, gene expression, and virus production in HeLa and A549 cells. Subsequently, the $\mathrm{m}^{6} \mathrm{~A}$ sites in the viral $G$ gene, the most abundant $\mathrm{m}^{6} \mathrm{~A}$ enrichment gene, are mutated in an infectious cDNA clone of RSV. The resultant $\mathrm{m}^{6} \mathrm{~A}$ deficient rgRSVs have significant defects in replication, gene expression, spread, and virus release in A549 cells and primary well differentiated human airway epithelial (HAE) cultures. These $\mathrm{m}^{6} \mathrm{~A}$ mutated rgRSVs are defective in viral replication in the upper and lower respiratory tract of cotton rats and produce less pathology in the lungs. Importantly, we find that one $\mathrm{m}^{6} \mathrm{~A}$-mutated rgRSV is completely attenuated in cotton rats yet retains a wild-type level of immunogenicity. Collectively, these results reveal that $\mathrm{m}^{6} \mathrm{~A}$ upregulates each step in the RSV replication cycle and viral pathogenesis, and identify $\mathrm{m}^{6} \mathrm{~A}$ as a new target for the rational design of live attenuated vaccine candidates and antiviral drugs for RSV.

\section{Results}

The RSV genome and antigenome/mRNAs are $\mathbf{m}^{\mathbf{6}} \mathbf{A}$ methylated. RSV has a NNS RNA genome of 15,222 nucleotides (RSV A2 strain). As is typical for NNS RNA viruses, replication of the viral genomic RNA (vgRNA) produces an exact, positive-sense full-length complementary RNA (cRNA) antigenome ${ }^{44}$. Both the genome and antigenome are encapsidated by the nucleocapsid (N) protein and both types of nucleocapsids can be packaged into virions, as for many NNS RNA viruses ${ }^{45}$. To investigate whether RSV RNA contains $\mathrm{m}^{6} \mathrm{~A}$, RNA was extracted from highly purified virions grown in HeLa cells, and the purity of RNA was examined by real-time RT-PCR to ensure that they were free from any contamination of host RNAs and viral mRNAs (Supplementary Fig. 1). The presence of $\mathrm{m}^{6} \mathrm{~A}$ in viral RNA was quantified by liquid chromatography-tandem mass spectrometry (LC-MS/MS). We found that $\sim 0.7 \%$ of the $\mathrm{A}$ bases were $\mathrm{m}^{6} \mathrm{~A}$ methylated in RSV viral RNAs, a somewhat higher level than the host mRNAs (0.1-0.4\%).

To locate the $\mathrm{m}^{6} \mathrm{~A}$ sites on RSV RNA, we sonicated virion RNA and subjected it to $\mathrm{m}^{6} \mathrm{~A}$-specific antibody immunoprecipitation followed by high-throughput sequencing ( $\mathrm{m}^{6} \mathrm{~A}$-seq), then mapped all the reads onto either the genome or antigenome sequence. Several $\mathrm{m}^{6} \mathrm{~A}$ peaks were identified on both strands of the viral RNA (Supplementary Fig. 2A and Fig. 1a). The RSV antigenomic RNA contained major $\mathrm{m}^{6} \mathrm{~A}$ peaks in the regions complementary to the $N, P, G$, and $F$ genes and in the regions complementary to the two regulatory elements, the gene end $(g e)$ sequence of $N$ and the intergenic ( $i g$ ) sequence between the $P$ and $M$ genes in the genome (Fig. 1a, and Supplementary Fig. 2A and Supplementary Table 1). In the genomic RNA, eleven $\mathrm{m}^{6} \mathrm{~A}$ peaks were detected in the NS2, $N, P, M, G$, and $L$ genes and four regulatory elements including the gene start ( $g s)$ of NS2, ig between $P$ and $M$, ge of $M$, ig between $M$ and $S H$, ge of $G$, and ig between $G$ and $F$ (Fig. la and Supplementary Fig. 2A and Supplementary Table 1). Since we used a recombinant RSV harboring GFP between the leader and the NS1 gene (rgRSV), we also searched whether GFP region contains $\mathrm{m}^{6} \mathrm{~A}$. An $\mathrm{m}^{6} \mathrm{~A}$ peak with a size of $60 \mathrm{nt}$ was detected in GFP gene in genome (Supplementary Table 1 ). No $\mathrm{m}^{6} \mathrm{~A}$ peak was found in GFP region in antigenome. The $G$ gene regions from both genome and antigenome have the strongest $\mathrm{m}^{6} \mathrm{~A}$ enrichment with peak size of $822 \mathrm{nt}$ and $672 \mathrm{nt}$, respectively, indicating that there may be multiple adjacent $\mathrm{m}^{6} \mathrm{~A}$ sites in these regions. Together, these results confirm that both RSV genome and antigenome RNAs contain $\mathrm{m}^{6} \mathrm{~A}$. 

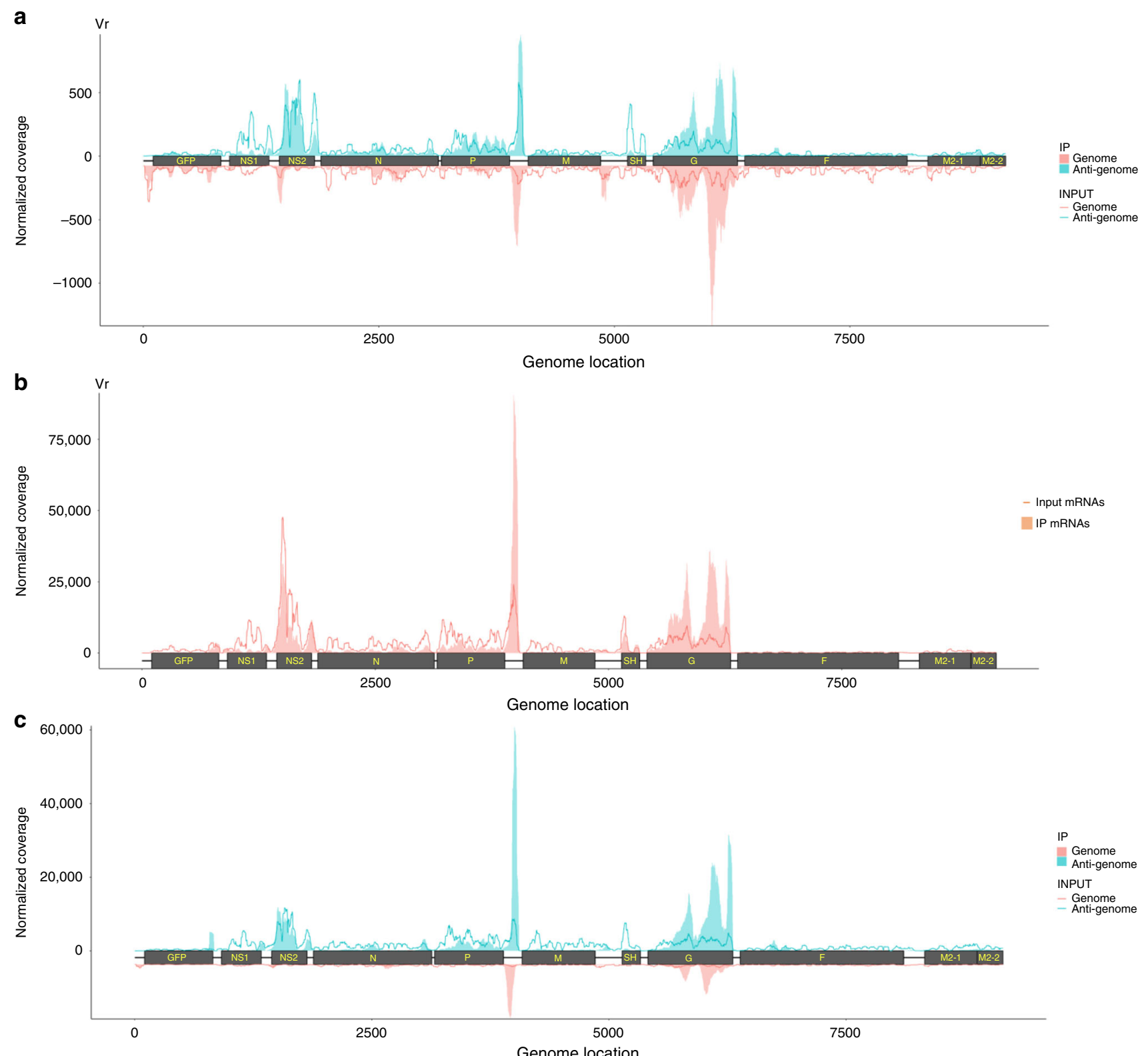

IP Genome INPUT - Genome

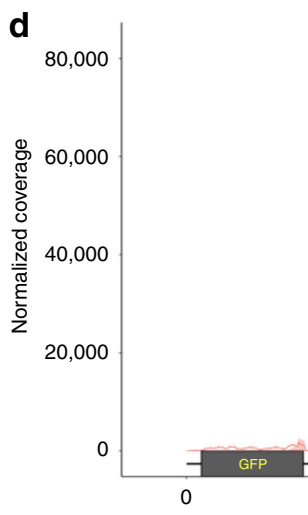

Genome location

nput mRNA

We also mapped $\mathrm{m}^{6} \mathrm{~A}$ peaks in mRNAs purified from RSVinfected cells. To do this, total RNA was isolated from rgRSVinfected HeLa cells, enriched for mRNA by binding to oligo dT, and subjected to $\mathrm{m}^{6} \mathrm{~A}$-seq. As RSV mRNAs contain poly $(\mathrm{A})$ and are subsequently detected from poly $(\mathrm{dT})$-enriched $\mathrm{m}^{6} \mathrm{~A}$-seq, we identified $16 \mathrm{~m}^{6} \mathrm{~A}$ peaks from RSV mRNAs (Fig. $1 \mathrm{~b}$,
Supplementary Fig. 2B and Supplementary Table 2) which largely overlapped with those of the antigenome (Fig. 1a, Supplementary Fig. 2A and Supplementary Table 1). Interestingly, the $G$ gene transcript has the strongest $\mathrm{m}^{6} \mathrm{~A}$ enrichment with a $846 \mathrm{bp}$ peak size. In addition, no $\mathrm{m}^{6} \mathrm{~A}$ peak was detected in GFP mRNA in virus-infected HeLa cells. 
Fig. 1 The RSV genome and antigenome/mRNAs are $\mathrm{m}^{6} \mathrm{~A}$ methylated. a Distribution of $\mathrm{m}^{6} \mathrm{~A}$ peaks in the RSV antigenome and genome of virions grown in HeLa cells. Confluent HeLa cells were infected by rgRSV at an MOI of 1.0, supernatant was harvested at $36 \mathrm{~h}$ post-infection. RSV virions were purified by sucrose gradient ultracentrifugation. Total RNAs were extracted from purified virions and were subjected to $\mathrm{m}^{6} \mathrm{~A}$-specific antibody immunoprecipitation followed by high-throughput sequencing $\left(\mathrm{m}^{6} \mathrm{~A}-\mathrm{seq}\right)$. A schematic diagram of partial RSV antigenome (complementary to regions from the leader sequence to $\mathrm{M} 2-2$ gene) is shown, as most $\mathrm{m}^{6} \mathrm{~A}$ peaks are clustered in these regions. $\mathrm{m}^{6} \mathrm{~A}$ sites in full-length antigenome and genome are shown in Supplementary Fig. 2. The normalized coverage from $\mathrm{m}^{6} \mathrm{~A}$-seq of RSV RNA showing the distribution of $\mathrm{m}^{6} \mathrm{~A}$-immunoprecipitated (IP) reads mapped to the RSV

antigenome (blue block) and genome (pink block). The baseline distributions for antigenome and genome from input sample are shown as a blue and pink line respectively. Data presented are the averages from two independent virion samples $(n=2)$. $\mathbf{b}$ Distribution of $\mathrm{m}^{6} \mathrm{~A}$ peaks in the RSV mRNAs from RSVinfected HeLa cells. Confluent HeLa cells were infected by rgRSV at an MOI of 1.0, cell lysates were harvested at $36 \mathrm{~h}$ post-infection. Total RNAs were extracted from cell lysates, and were enriched for mRNA by binding to oligo $d T$, and subjected to $\mathrm{m}^{6} \mathrm{~A}$-seq. The distribution of $\mathrm{m}^{6} \mathrm{~A}$-immunoprecipitated (IP) reads were mapped to the RSV mRNAs (pink block). The baseline distributions for mRNAs from input sample are shown as a pink line. Data presented are the averages from two independent virus-infected HeLa cell samples $(n=2)$. c Distribution of $\mathrm{m}^{6} \mathrm{~A}$ peaks in the RSV antigenome and genome of virions grown in A549 cells. Data presented are the averages from two independent virion samples $(n=2)$. $\mathbf{d}$ Distribution of $m^{6} \mathrm{~A}$ peaks in the RSV mRNAs from RSV-infected A549 cells. Data presented are the averages from two independent virus-infected A549 cell samples $(n=2)$

We next performed $\mathrm{m}^{6} \mathrm{~A}$-seq of rgRSV grown in A549 cells, a relevant cell line for RSV infection. Similar to HeLa cells, we found that RSV genome, antigenome, and mRNAs were $\mathrm{m}^{6} \mathrm{~A}$ methylated in A549 cells (Fig. 1c, d, and Supplementary Fig. 2C, D). For virion RNAs, a total of 9 and $15 \mathrm{~m}^{6} \mathrm{~A}$ peaks were identified in the genome and antigenome, respectively (Fig. 1c and Supplementary Fig. 2C and Supplementary Table 3). Similar to virions grown in HeLa cells, the location of $\mathrm{m}^{6} \mathrm{~A}$ peaks identified from genome and antigenome largely overlap. $G$ gene regions from both genome and antigenome have the strongest $\mathrm{m}^{6} \mathrm{~A}$ enrichment with 696 and 846 bp peak size, respectively. An $\mathrm{m}^{6} \mathrm{~A}$ peak was detected in GFP gene in antigenome but no $\mathrm{m}^{6} \mathrm{~A}$ peak was detected in GFP gene in genome. For the RNAs extracted from virus-infected cells, a total of $18 \mathrm{~m}^{6} \mathrm{~A}$ peaks were identified in RSV mRNAs (Fig. 1d and Supplementary Fig. 2D and Supplementary Table 4). Again, the $G$ gene transcript has the strongest $\mathrm{m}^{6} \mathrm{~A}$ enrichment with $1046 \mathrm{bp}$ peak size. In addition, one $\mathrm{m}^{6} \mathrm{~A}$ peak was found in GFP mRNA in infected A549 cells.

We next analyzed the overlapping regions based on $\mathrm{m}^{6} \mathrm{~A}$-seq data from HeLa and A549 cells (Supplementary Tables 5 and 6). For virion RNA, six and four overlapping regions were identified in the genome ( $g s$ of NS2, NS2, $N, P$, ig between $P$ and $M$, and $G$ ) and antigenome $(N, M, G$, and $F)$, respectively (Supplementary Table 5). For RNAs purified from RSV-infected cells, 11 overlapping $\mathrm{m}^{6} \mathrm{~A}$ peaks were also found in mRNAs, respectively (Supplementary Table 6). Although there are some differences, the majority of $\mathrm{m}^{6} \mathrm{~A}$ peaks are highly conserved between the two cell lines suggesting that RSV utilizes the host $\mathrm{m}^{6} \mathrm{~A}$ machinery to methylate these specific sites.

RSV infection alters the $\mathbf{m}^{\mathbf{6}} \mathbf{A}$ distribution of host RNAs. We next determined the effects of RSV infection on the abundance and distribution of $\mathrm{m}^{6} \mathrm{~A}$ on cellular transcripts. Metagene analysis showed that RSV-infected and mock-infected HeLa cells have $\mathrm{m}^{6} \mathrm{~A}$ peaks enriched near the start and stop codons of open reading frames (Supplementary Fig. $3 \mathrm{~A}$ ), which is consistent with the known distribution of $\mathrm{m}^{6} \mathrm{~A}$ sites on transcripts ${ }^{10-12}$. Unlike the distribution of $\mathrm{m}^{6} \mathrm{~A}$ peaks on mRNA, the peaks are mostly uniformly distributed on lncRNA with a slightly more enrichment at its $5^{\prime}$ end (Supplementary Fig. 3B). The distribution of $\mathrm{m}^{6} \mathrm{~A}$ peaks in each annotation also recapitulate $\mathrm{m}^{6} \mathrm{~A}$ site distribution $^{10-12}$ with the majority of peaks residing in the CDS and 3' UTR regions (Supplementary Fig. 3C, D). Differential peak analysis using the count based QNB test ${ }^{46}$ identified 2256 differentially methylated peaks (Supplementary Data 1). Analysis of RNA-seq data from the host cell (HeLa) revealed over 9000 differentially expressed genes at an adjusted $P$ value cutoff of 0.05 (Supplementary Data 2). These data suggest RSV infection significantly altered both the epitranscriptome and the transcriptome of the host cells. Pathway enrichment analysis shows differentially expressed genes are enriched in pathways including cell cycle, metabolism, autophagy, RNA synthesis and transport, and response to viral infection (Supplementary Fig. 3E).

As expected, the distribution of $\mathrm{m}^{6} \mathrm{~A}$ sites was highly conserved between cell lines (Supplementary Fig. 4A-D). RSV infection altered the expression of over 7000 host cell genes in A549 cells (Supplementary Data 3) involved in a series of signal pathways (Supplementary Fig. 4E) but very few $\mathrm{m}^{6} \mathrm{~A}$ peaks were found to be differentially methylated (Supplementary Data 4). We also analyzed the differentially expressed genes which are overlapped in pathways between the HeLa and A549 cells. Many of these overlapped differentially expressed genes are involved cell cycle, metabolism, TNFa signaling, and RNA transport (Supplementary Fig. 4F). Therefore, RSV infection may have widespread effects on host gene expression partially attributed to alteration of the deposition of $\mathrm{m}^{6} \mathrm{~A}$.

$\mathrm{m}^{6} \mathrm{~A}$ reader proteins positively regulate $\mathrm{RSV}$ replication. To begin to explore the role of $\mathrm{m}^{6} \mathrm{~A}$ modification in RSV replication and gene expression, we first took advantage of HeLa cells that stably overexpress $\mathrm{m}^{6} \mathrm{~A}$ "reader" proteins, YTHDF1, YTHDF2, and YTHDF3 (Fig. 2a). As shown in Fig. 2b, stronger GFP expression (more green cells, brighter cells) was observed in HeLa cells overexpressing YTHDF1-3 compared to the vector control. Quantification by flow cytometry showed that significantly more GFP-positive cells and higher GFP density were detected in HeLa cells overexpressing $\mathrm{m}^{6} \mathrm{~A}$ reader proteins than in the vector control $(P<0.05)$ (Fig. 2c and Supplementary Fig. 5).

We next measured the expression of RSV F, G, and N proteins. As shown in Fig. 2d, more F, G, and N proteins were detected in all three YTHDF-overexpressing HeLa cell lines. Quantitative analysis showed a dramatic increase in viral protein expression during the first $12 \mathrm{~h}$ although later time points were not as large (Fig. 2e-g). Next, we measured the release of infectious virus particles in a single-step growth curve. The RSV titer was significantly increased in all three YTHDF-overexpressing cell lines (Fig. 2h) $(P<0.05$ or 0.01$)$. Overexpression of YTHDF2 had the most dramatic impact on virus production, increasing RSV titer by $1-2$ logs compared to the vector control HeLa cells $(P<$ 0.05 or 0.01 ) (Fig. $2 \mathrm{~h}$ ).

The upregulating role of $\mathrm{m}^{6} \mathrm{~A}$ reader proteins on RSV replication was also confirmed in HeLa cells transfected with plasmids expressing YTHDF1-3 (Supplementary Fig. 6A). Compared to HeLa cells stably overexpressing YTHDF1-3 (Fig. 2d), transient overexpression of YTHDF1-3 led to a more robust enhancement of $F$ and $G$ protein synthesis (Supplementary Fig. 6B) and GFP expression (Supplementary Fig. 6C). 
a

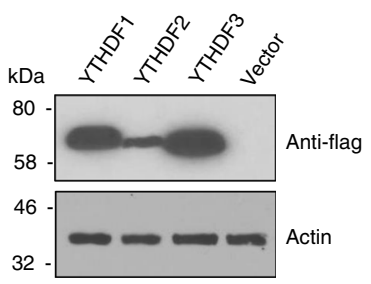

b

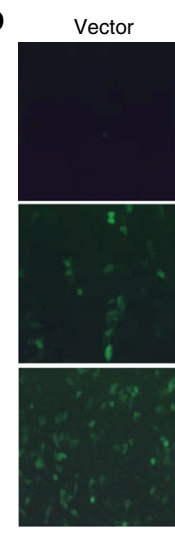

YTHDF

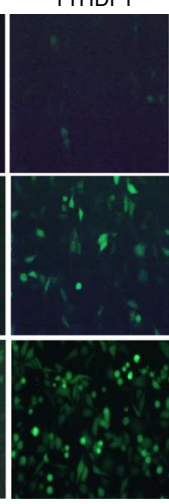

f

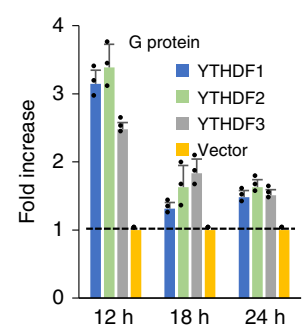

C

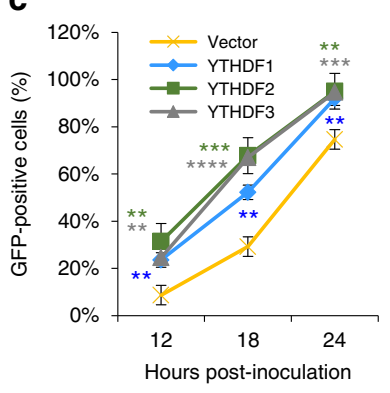

YTHDF2
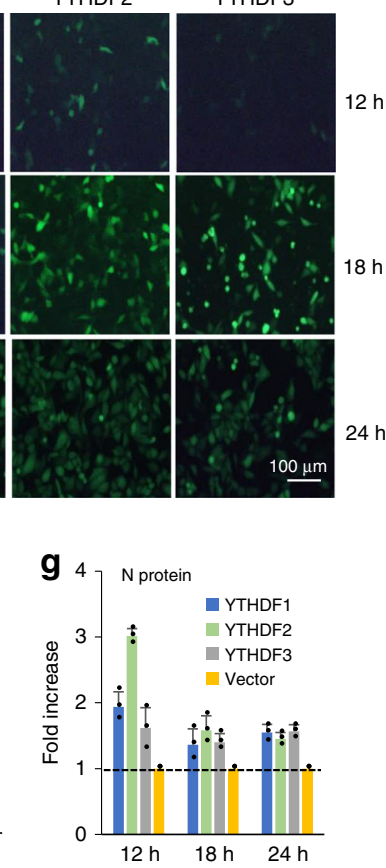

d

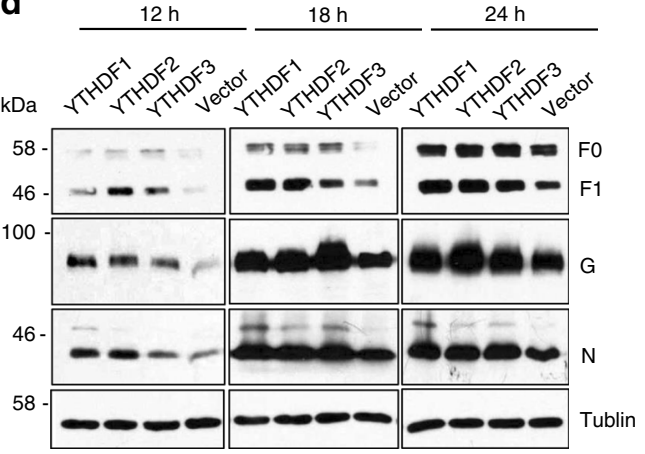

e

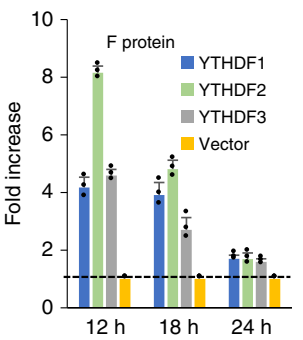

h

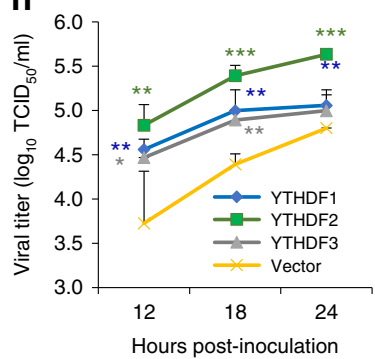

i

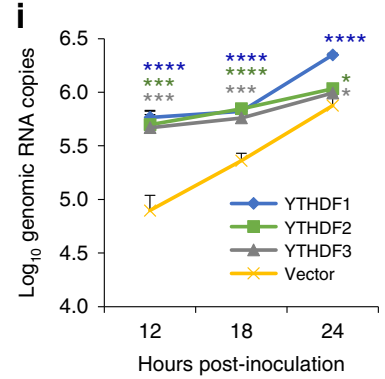

j

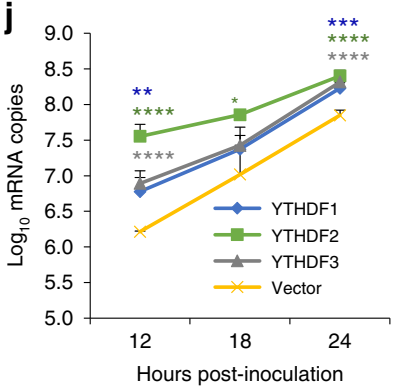

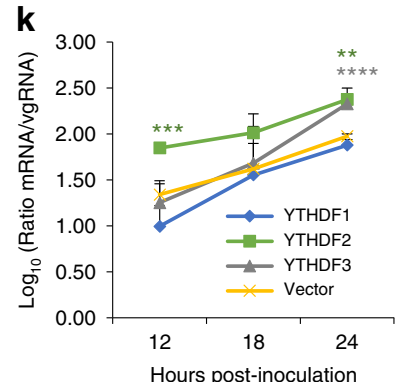

Fig. 2 YTHDF1, 2, 3 (reader) proteins promote RSV replication, gene expression, and progeny virus production. a Detection of YTHDF1, 2, 3 in HeLa cells stably overexpressing YTHDF1-3. Western blot confirmed the overexpression of YTHDF1-3 proteins in HeLa cells using anti-Flag antibody. $\mathbf{b}$ YTHDF1, 2, 3 enhance GFP expression in rgRSV-infected cells. HeLa cells stably overexpressing these YTHDF proteins were infected with rgRSV at an MOI of 0.1, and GFP expression was monitored at the indicated times by fluorescence microscopy. Micrographs with $\times 10$ magnification (scale bar of $100 \mu \mathrm{m}$ ) are shown. c YTHDF1, 2, 3 increase the number of GFP-positive cells quantified by flow cytometry. The $P$ value (Student's $t$-test) for YTHDF1 at 12,18 , and $24 \mathrm{~h}$ is ${ }^{\star}{ }^{\star} P=0.00297,{ }^{\star \star} P=0.00145$, and ${ }^{\star \star} P=0.00202$, respectively; for YTHDF2 at 12,18 , and $24 \mathrm{~h}$ is ${ }^{\star \star} P=0.00318,{ }^{\star \star *} P=0.000892$, and ${ }^{\star \star} P=0.00312$, respectively; for YTHDF3 at 12,18 , and $24 \mathrm{~h}$ is ${ }^{\star \star} P=0.00119$, ${ }^{\star \star \star}{ }^{\star \star} P=5.19 \times 10^{-5}$, and ${ }^{\star \star \star} P=0.000647$, respectively. $\mathbf{d}$ YTHDF1, 2,3 enhance RSV protein expression. Total cell extracts were harvested from rgRSV-infected HeLa cells at the indicated times and subjected to western blot using antibody against RSV N, F, or G protein. Western blots shown are the representatives of three independent experiments. RSV F (FO + F1) (e), G (f), and N (g) proteins were quantified by Image J Software. Data are expressed as mean of three independent experiments \pm standard deviation. $\mathbf{h}$ YTHDF1, 2, 3 increase RSV progeny virus production. The release of infectious RSV particles was monitored by a single-step growth curve. Virus titer was measured by TCID 50 . The $P$ value (Student's $t$-test) for YTHDF1 at 12,18 , and $24 \mathrm{~h}$ is ${ }^{\star \star} P=0.0349$, ${ }^{\star \star} P=0.00797$, and ${ }^{\star \star} P=0.00741$, respectively; for $Y$ THDF2 at 12,18 , and $24 \mathrm{~h}$ is ${ }^{\star \star} P=$ $0.0176,{ }^{\star \star \star} P=0.000279$, and ${ }^{\star \star \star} P=1.58 \times 10^{-25}$, respectively; for YTHDF3 at 12 and $18 \mathrm{~h}$ is ${ }^{\star} P=0.0487$ and ${ }^{* \star} P=0.00317$, respectively. $\mathbf{i}$ YTHDF1, 2,3 enhance RSV genomic RNA replication. Total RNA was purified from rgRSV-infected cells using TRizol, and genomic RNA was quantified by real-time RT-

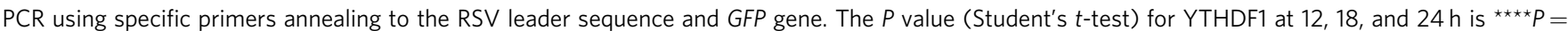
$3.68 \times 10^{-5},{ }^{\star \star \star \star} P=5.46 \times 10^{-5}$, and ${ }^{\star \star \star \star} P=4.96 \times 10^{-5}$, respectively; for $Y$ THDF2 at 12,18 , and $24 \mathrm{~h}$ is ${ }^{\star \star \star} P=0.000237,{ }^{\star \star \star \star} P=1.48 \times 10^{-5}$, and ${ }^{\star} P=$ 0.0184 , respectively; for YTHDF3 at 12,18 , and $24 \mathrm{~h}$ is ${ }^{\star \star \star} P=0.000165,{ }^{\star \star \star} P=0.000128$, and ${ }^{\star} P=0.0475$, respectively. j YTHDF1, 2,3 enhance mRNA transcription. Viral mRNA was separated from total RNA using the Dynabeads mRNA isolation kit and quantified by real-time PCR using primers annealing to the NS1 gene. The $P$ value (Student's $t$-test) for YTHDF1 at 12 and $24 \mathrm{~h}$ is ${ }^{\star \star} P=0.00794$ and ${ }^{\star \star \star} P=0.000218$, respectively; for $Y$ THDF2 at 12,18 , and $24 \mathrm{~h}$ is ${ }^{\star \star \star \star} P=4.94 \times 10^{-6},{ }^{\star} P=0.0430$, and ${ }^{* \star \star \star} P=3.46 \times 10^{-5}$, respectively; for YTHDF3 at 12 and $24 \mathrm{~h}$ is ${ }^{\star \star \star \star} P=5.93 \times 10^{-6}$ and ${ }^{\star \star * \star} P=2.39 \times 10^{-5}$, respectively. $\mathbf{k}$ Ratio between mRNA and genomic RNA. The ratio between NS1 mRNA and genomic RNA was calculated for each cell line. All results are from three independent experiments. Flow cytometry data are expressed as mean of three independent experiments \pm standard deviation. RNA copy and viral titer are the geometric mean titer (GMT) of three independent experiments \pm standard deviation. The $P$ value (Student's $t$-test) for YTHDF2 at 12 and $24 \mathrm{~h}$ is ${ }^{\star \star \star} P=0.000601$ and ${ }^{\star \star} P=0.00130$, respectively; for YTHDF3 at $24 \mathrm{~h}$ is ${ }^{\star \star \star \star} P=0.000599$. Data were analyzed using Student's $t$-test and statistical differences were indicated as ${ }^{\star} P<0.05 ;{ }^{\star \star} P<0.01$; ${ }^{\star \star \star} P<0.001$; and ${ }^{\star \star \star \star} P P<0.0001$ 

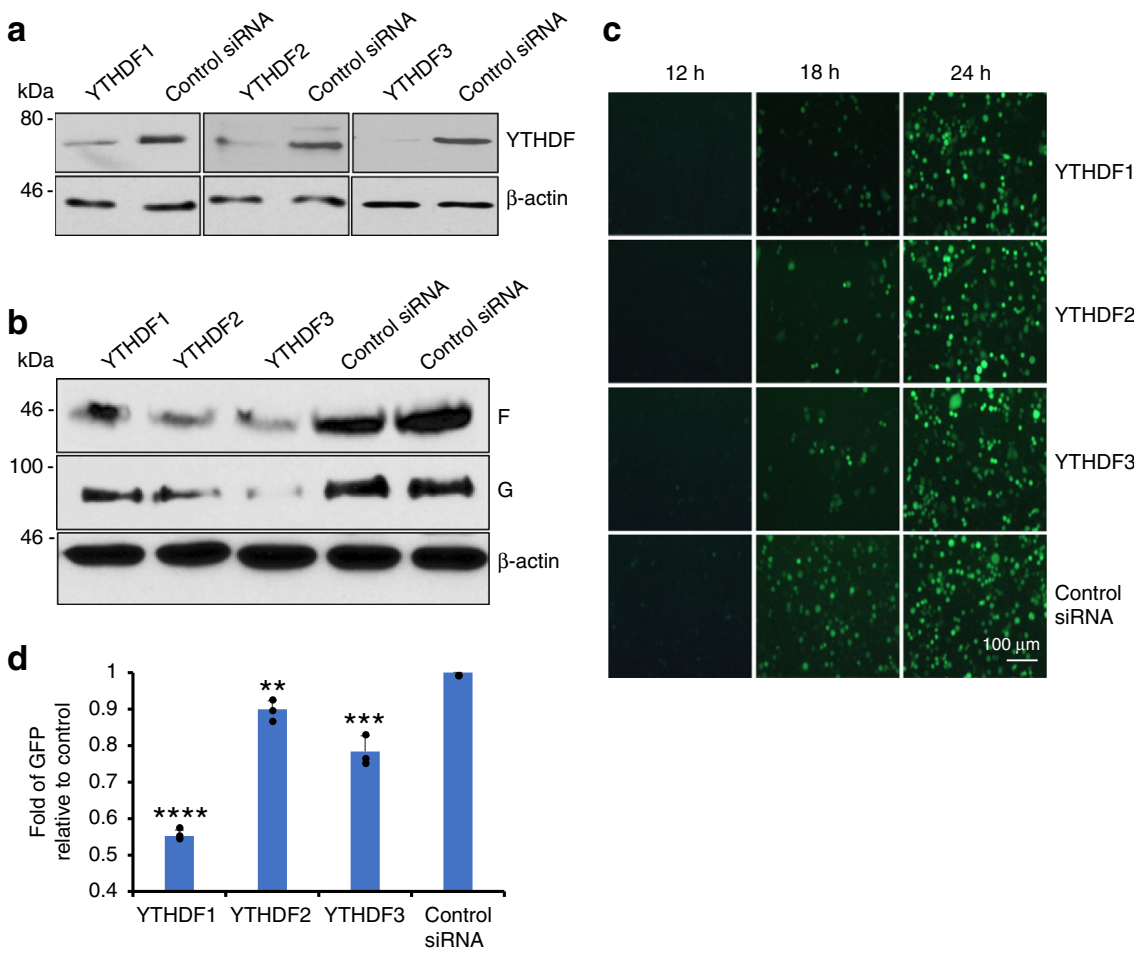

Fig. 3 Knockdown of endogenous YTHDF1, 2, 3 (reader) proteins diminishes RSV gene expression. HeLa cells were transfected with 150 pmole of siRNA targeting YTHDF1, 2, 3 or control siRNA. At $36 \mathrm{~h}$ post-transfection, cells were infected with rgRSV at an MOI of 0.5. a Immunoblot analysis of YTHDF1, 2, 3 in HeLa cells transfected with siRNA. b Immunoblot analysis of RSV G and F proteins. c Dynamics of GFP expression in YTHDF1, 2, 3 protein-depleted HeLa cells. Micrographs with $\times 10$ magnification (scale bar of $100 \mu \mathrm{m}$ ) are shown. d Quantification of GFP-positive cells by flow cytometry at $18 \mathrm{~h}$ postinoculation. Fold of GFP signal compared to the control is shown. Western blots and GFP images shown are the representatives of three independent experiments. Flow cytometry data are expressed as mean of three independent experiments \pm standard deviation. The $P$ value (Student's $t$-test) for YTHDF1, 2, and 3 is ${ }^{\star \star \star \star} P=1.10 \times 10^{-6},{ }^{\star \star} P=0.00170$, and ${ }^{\star \star \star} P=0.000972$, respectively

We further analyzed viral replication and gene expression in A549 cells. Similar to the observations in HeLa cells, enhanced F, $\mathrm{G}$, and $\mathrm{N}$ protein synthesis (Supplementary Fig. 7A) and GFP expression (Supplementary Fig. 7B) was detected when YTHDF13 proteins were overexpressed. We also tested RSV replication in Vero cells, the WHO-approved cell line for production of RSV live attenuated vaccine candidates. Similarly, $\mathrm{m}^{6} \mathrm{~A}$ reader protein (YTHDF1) enhanced RSV protein synthesis in Vero cells (Supplementary Fig. 7C). Thus, we observed a pro-viral function for $\mathrm{m}^{6} \mathrm{~A}$ in all three cell lines. It should be noted that overexpression of YTHDF1 protein (a representative of reader proteins) in A549 cells did not significantly affect the growth or survival of the cells (Supplementary Fig. 8A, B).

We also measured the RSV genomic RNA (the replication product) and mRNAs (the transcription product) in HeLa cells by real-time RT-PCR. Overexpression of YTHDF1-3 significantly increased both RSV genomic RNA (Fig. 2i) and mRNA synthesis (Fig. 2j). Overexpression of YTHDF1 and 3 did not alter the balance between the synthesis of genomic RNA and mRNA whereas overexpression of YTHDF2 led to a more dramatic increase in replication than transcription (Fig. 2k). It appears that overexpression of YTHDF1-3 enhanced the ability of the RSV polymerase to both replicate and transcribe.

As a complementary approach, we also tested RSV replication and gene expression in HeLa cells when $\mathrm{m}^{6} \mathrm{~A}$ reader proteins were knocked down by siRNA. Counting live cells by flow cytometry showed that siRNA targeting YTHDF1 did not significantly alter cell survival (Supplementary Fig. 8C, D). Knockdown of individual, endogenous YTHDF1-3 proteins (Fig. 3a) significantly reduced viral $F$ and $G$ protein synthesis
(Fig. 3b) and GFP expression (Fig. 3c, d) relative to the control siRNA transfected cells. Collectively, these results demonstrate that $\mathrm{m}^{6} \mathrm{~A}$ binding proteins promote RSV genome replication, mRNA transcription, and as a result, viral protein expression, and progeny virus production.

$\mathrm{m}^{6} \mathrm{~A}$ writer proteins positively regulate $\mathrm{RSV}$ replication. The internal $\mathrm{m}^{6} \mathrm{~A}$ addition is catalyzed by host methyltransferases termed $\mathrm{m}^{6} \mathrm{~A}$ writer proteins (METTL3 and METTL14) ${ }^{18}$. We next examined the role of the $\mathrm{m}^{6} \mathrm{~A}$ writer proteins in RSV replication and protein expression. More $F$ and $G$ protein synthesis (Fig. 4a) and GFP expression (Fig. 4b, c) were observed when METTL3 and METTL14 were overexpressed in HeLa cells. In contrast, less $\mathrm{F}$ and $\mathrm{G}$ proteins were synthesized (Fig. $4 \mathrm{~d}$ ) and less GFP was expressed (Fig. 4e, f) when endogenous METTL3, METTL14, or both, were knocked down. siRNA targeting METTL3 did not significantly alter cell survival (Supplementary Fig. 8C, D). These results suggest that modification of RSV RNA by $\mathrm{m}^{6} \mathrm{~A}$ writers facilitates RSV replication and gene expression.

Next, we determined whether alteration of $\mathrm{m}^{6} \mathrm{~A}$ writer proteins can alter the level of $\mathrm{m}^{6} \mathrm{~A}$ level in viral RNA. As shown in Fig. $4 \mathrm{~g}$, $\mathrm{h}$, the $\mathrm{m}^{6} \mathrm{~A}$ contents in viral RNA of virus from METTL3 and METTL14-overexpressed cells were significantly higher ( 26\% increase) than viral RNA of particles from vector-transfected cells. Knockdown of METTL3 and METTL14 led to $70 \%$ of reduction in $\mathrm{m}^{6} \mathrm{~A}$ content in viral RNA (Fig. $4 \mathrm{i}, \mathrm{j}$ ). These experiments suggest that manipulation of $\mathrm{m}^{6} \mathrm{~A}$ writer proteins lead to enhanced or reduced levels of $\mathrm{m}^{6} \mathrm{~A}$ in viral RNAs, which may in turn, affect viral replication and gene expression. 

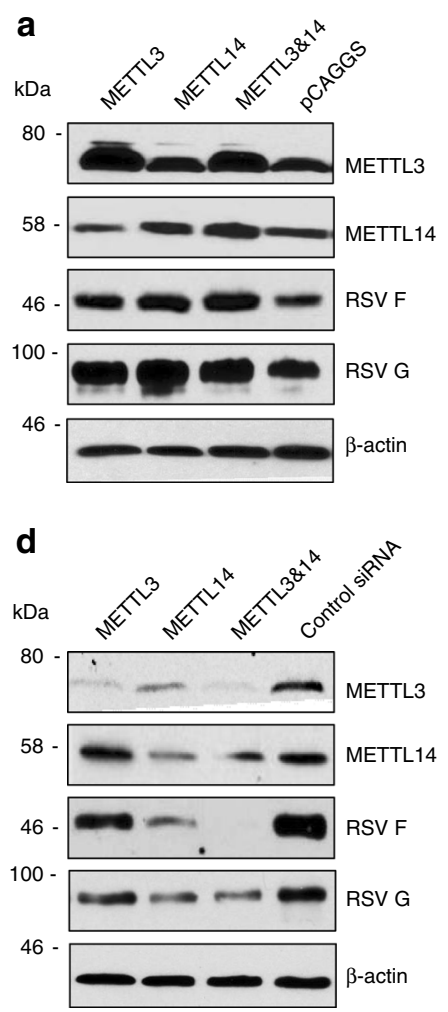

b

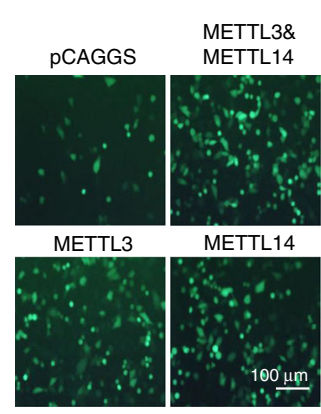

e

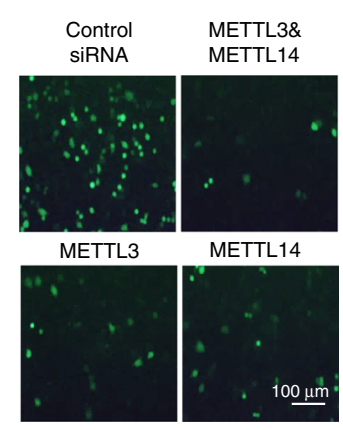

C

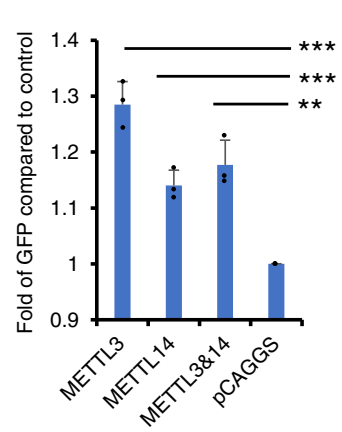

$\mathbf{f}$

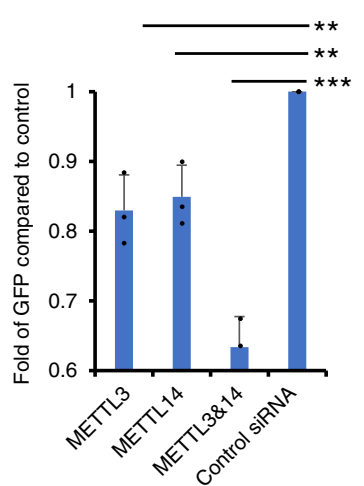

g

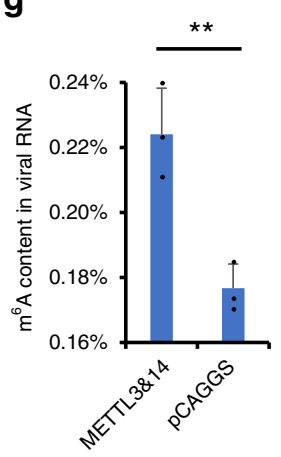

h

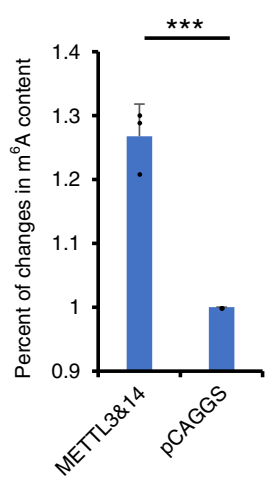

i

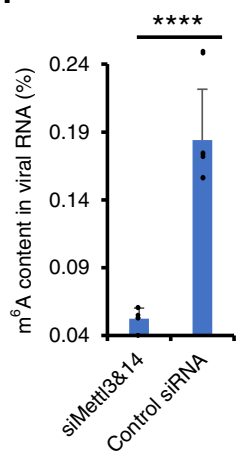

j

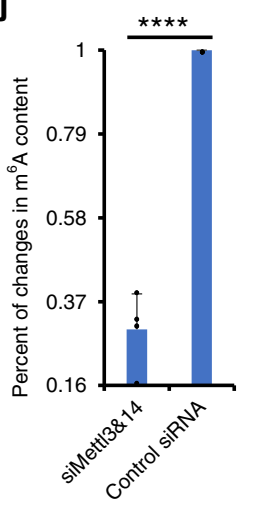

Fig. 4 Effects of $m^{6} \mathrm{~A}$ writer proteins on RSV gene expression. a Overexpression of $\mathrm{m}^{6} \mathrm{~A}$ writer proteins enhances RSV gene expression. HeLa cells were transfected with plasmids encoding METTLE3 and/or METTL14, followed by rgRSV infection at an MOI of 0.5. At $18 \mathrm{~h}$ post-infection, cell lysates were harvested for western blot analysis. $\mathbf{b}$ Overexpression of $\mathrm{m}^{6} \mathrm{~A}$ writer proteins enhances RSV expression of GFP. The GFP expression was monitored by fluorescence microscopy. Representative micrographs with $\times 10$ magnification (scale bar of $100 \mu \mathrm{m}$ ) at $18 \mathrm{~h}$ post-infection were shown. c Quantification of GFP-positive cells by flow cytometry at $18 \mathrm{~h}$ post-infection. Fold of GFP signal compared to the control is shown. The $P$ value (Student's $t$-test) for METTL3, METTL14, and METTL3 \& METTL14 is ${ }^{\star \star \star} P=0.000276$, ${ }^{\star \star \star} P=0.000873$, and ${ }^{\star \star} P=0.00228$, respectively. $\mathbf{d}$ Knockdown of $\mathrm{m}^{6} \mathrm{~A}$ writer proteins diminishes RSV gene expression. HeLa cells were transfected with siRNA targeting METTL3 and/or METTL14, followed by rgRSV infection at an MOI of 0.5. At $18 \mathrm{~h}$ post-infection, cell lysates were harvested for western blot analysis. e Knockdown of $\mathrm{m}^{6} \mathrm{~A}$ writer proteins diminishes GFP expression. Micrographs with $\times 10$ magnification (scale bar of $100 \mu \mathrm{m}$ ) are shown. $\mathbf{f}$ Quantification of GFP-positive cells by flow cytometry. Fold of GFP signal compared to the control is shown. Flow cytometry data are expressed as mean \pm standard deviation. The $P$ value (Student's t-test) for METTL3, METTL14, and METTL3 \& METTL14 is ${ }^{\star \star} P=0.00441,{ }^{\star \star} P=0.00458$, and ${ }^{\star \star \star \star} P=0.000134$, respectively. $\mathbf{g}$ Overexpression of $\mathrm{m}^{6} \mathrm{~A}$ writer proteins enhances $\mathrm{m}^{6} \mathrm{~A}$ level in viral RNA. Confluent A549 cells were transfected with plasmids encoding Mettl3 and Mett14 or vector pCAGGS, followed by rgRSV infection. RSV particles were harvested and purified. The $\mathrm{m}^{6} \mathrm{~A}$ content in viral RNA was determined as described in Materials and Methods. The $P$ value (Student's $t$-test) is ${ }^{\star \star} P=0.00684$. $\mathbf{h}$ Fold increase in $\mathrm{m}^{6} \mathrm{~A}$ content in viral RNA compared to controls. The $P$ value (Student's $t$-test) is ${ }^{\star \star \star} P=0.000764$. $\mathbf{i}$ Knockdown of $\mathrm{m}^{6} \mathrm{~A}$ writer proteins reduces $\mathrm{m}^{6} \mathrm{~A}$ level in viral RNA. A549 cells were transfected with siRNA targeting METTL3 and METTL14 or control siRNA, followed by rgRSV infection. RSV particles were harvested and purified. The $\mathrm{m}^{6} \mathrm{~A}$ content in viral RNA was determined. The $P$ value (Student's $t$-test) is ${ }^{\star \star \star \star} P=$ $1.29 \times 10^{-7}$. j Fold reduction in $\mathrm{m}^{6} \mathrm{~A}$ content in viral RNA compared to controls. The $P$ value (Student's $t$-test) is ${ }^{\star \star \star} P=2.45 \times 10^{-12}$. Results are from three or four independent experiments

$\mathrm{m}^{6} \mathrm{~A}$ eraser proteins downregulated RSV replication. Internal $\mathrm{m}^{6} \mathrm{~A}$ modifications are reversible and can be removed by $\mathrm{m}^{6} \mathrm{~A}$ eraser proteins ${ }^{7,8}$. We thus examined the effects of overexpression of eraser proteins ALKBH5 or FTO, or both (Fig. 5). Overexpression of eraser proteins dramatically reduced RSV F and G protein expression by 80 - and 20 -fold, respectively (Fig. $5 \mathrm{a}$ ), and number of GFP cells by 1.3-2.7 times (Fig. 5b, c). Next, we knocked down ALKBH5 or FTO, or both, in HeLa cells, followed by rgRSV infection. siRNA targeting ALKBH5 did not significantly alter cell survival (Supplementary Fig. 8C, D). Knockdown of ALKBH5 and FTO enhanced the expression of F protein by 3 -fold, G protein by 5 -fold (Fig. 5 d), and number of GFP cells by 1.2 -fold (Fig. 5e, f) compared to the cells transfected with control siRNA. Therefore, overexpression of $\mathrm{m}^{6} \mathrm{~A}$ eraser proteins negatively regulated RSV replication and gene expression. We also determined whether overexpression and knockdown of eraser proteins can affect $\mathrm{m}^{6} \mathrm{~A}$ level of viral RNA. As shown in
Fig. $5 \mathrm{~g}, \mathrm{~h}$, the $\mathrm{m}^{6} \mathrm{~A}$ contents in viral RNA of virus from ALKBH5overexpressed cells led to $46 \%$ reduction. Knockdown of ALKBH5 led to 2.12-fold increases in $\mathrm{m}^{6} \mathrm{~A}$ abundance in viral RNA (Fig. 5i, j). Therefore, manipulation of $\mathrm{m}^{6} \mathrm{~A}$ eraser proteins can directly affect $\mathrm{m}^{6} \mathrm{~A}$ levels in viral RNAs, which may affect viral replication and gene expression.

RSV infection does not alter the translocation of $\mathrm{m}^{6} \mathrm{~A}$ proteins. To directly visualize the locations of the $\mathrm{m}^{6} \mathrm{~A}$ reader, writer, and eraser proteins, mock and rgRSV-infected HeLa cells were stained with antibodies specific to each $\mathrm{m}^{6} \mathrm{~A}$-related protein and analyzed by confocal microscopy. As shown in Fig. 6a and Supplementary Fig. 9, $\mathrm{m}^{6} \mathrm{~A}$ reader proteins (YTHDF1-3) were distributed in the cytoplasm in both mock and RSV-infected cells. In addition, viral $\mathrm{N}$ protein was partially co-localized with reader protein (YTHDF2) (Fig. 6a). In contrast, the majority of $\mathrm{m}^{6} \mathrm{~A}$ writer 
a
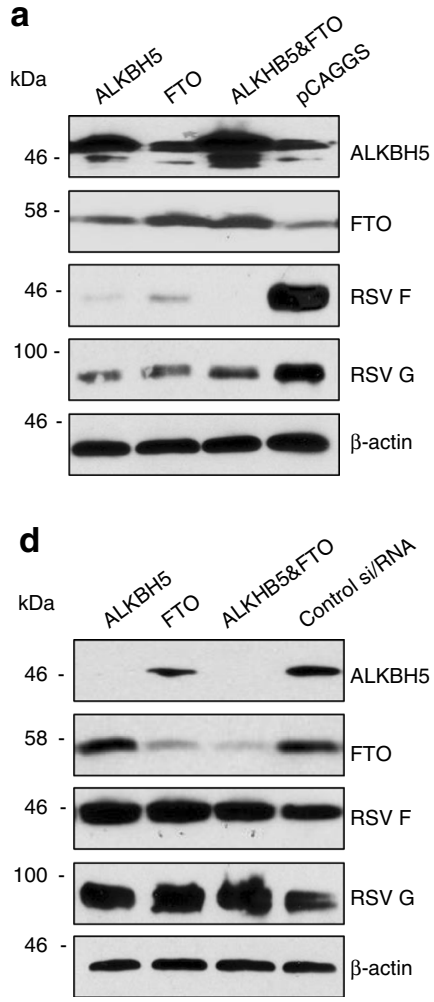

b

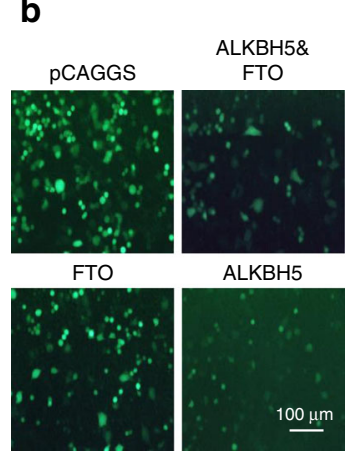

e

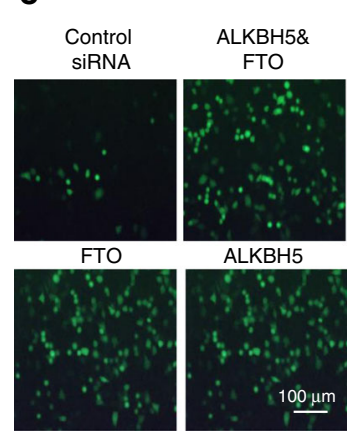

c

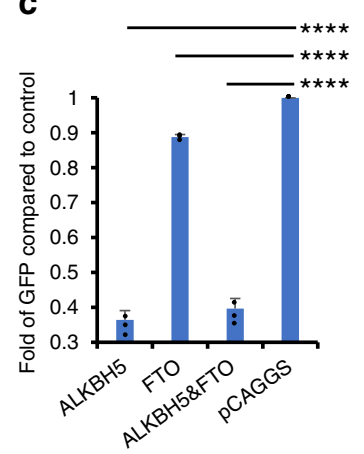

f

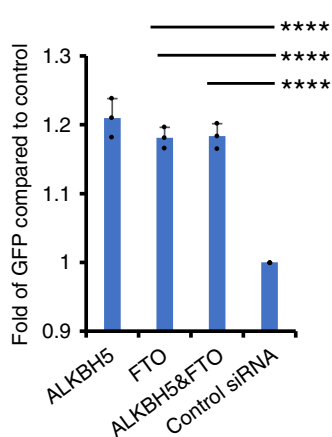

g

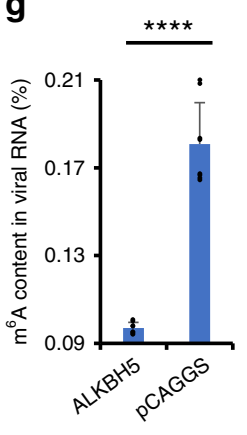

h

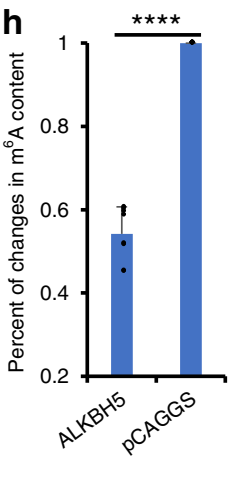

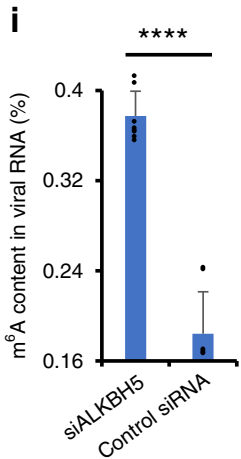

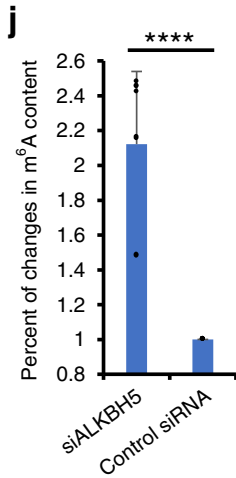

Fig. 5 Effects of $\mathrm{m}^{6} \mathrm{~A}$ eraser proteins on RSV gene expression. a Overexpression of $\mathrm{m}^{6} \mathrm{~A}$ eraser proteins diminishes RSV gene expression. HeLa cells were

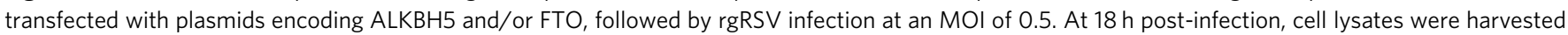
for Western blot analysis. b Overexpression of $\mathrm{m}^{6} \mathrm{~A}$ eraser proteins reduces GFP expression. The GFP expression was monitored by fluorescence microscopy. Representative micrographs with $10 \times$ magnification (scale bar of $100 \mu \mathrm{m}$ ) at $18 \mathrm{~h}$ post-infection were shown. c Quantification of GFP-positive cells by flow cytometry at $18 \mathrm{~h}$ post-infection. The $P$ value (Student's t-test) for ALKBH5, FTO, and ALKBH5\&FTO is ${ }^{\star \star \star \star} P=1.91 \times 10^{-6}, \star \star \star \star * P=1.34 \times$ $10^{-5}$, and ${ }^{\star \star \star \star} P=3.61 \times 10^{-6}$, respectively. $\mathbf{d}$ Knockdown of $\mathrm{m}^{6} \mathrm{~A}$ eraser proteins enhances RSV gene expression. HeLa cells were transfected with siRNA targeting ALKBH5 and/or FTO, followed by rgRSV infection at an MOI of 0.5. At $18 \mathrm{~h}$ post-infection, cell lysates were harvested for Western blot analysis. e Knockdown of $\mathrm{m}^{6} \mathrm{~A}$ eraser proteins enhances GFP expression. Micrographs with $10 \times$ magnification (scale bar of $100 \mu \mathrm{m}$ ) are shown. $\mathbf{f}$ Quantification of GFP-positive cells by flow cytometry. Fold of GFP signal compared to the control is shown. Western blots and GFP images shown are representatives of three independent experiments. Flow cytometry data are expressed as mean \pm standard deviation. The $P$ value (Student's $t$-test) for ALKBH5, FTO, and ALKBH5\&FTO is ${ }^{\star \star \star \star} P=2.06 \times 10^{-4}{ }^{\star \star \star \star \star} P=3.38 \times 10^{-5}$, and ${ }^{\star \star \star \star} P=6.50 \times 10^{-6}$, respectively. $\mathbf{g}$ Overexpression of $\mathrm{m}^{6} \mathrm{~A}$ eraser protein reduces $\mathrm{m}^{6} \mathrm{~A}$ level in viral RNA. A549 cells were transfected with plasmid encoding ALKBH5 or pCAGGS, followed by rgRSV infection. RSV particles were purified from supernatants. Virion RNA was subjected to $\mathrm{m}^{6} \mathrm{~A}$-IP. The $P$ value (Student's $t$-test) is ${ }^{\star \star \star \star} P=5.81 \times 10^{-9}$. $\mathbf{h}$ Fold reduction in $\mathrm{m}^{6} \mathrm{~A}$ content in viral RNA compared to controls. The $P$ value (Student's $t$-test) is ${ }^{\star \star \star \star} P=1.17 \times 10^{-11}$. i Knockdown of $m^{6} A$ eraser protein increases $m^{6} A$ level in viral RNA. A549 cells were transfected with siRNA targeting ALKBH5 or control siRNA, followed by rgRSV infection. RSV particles were purified. Virion RNA was subjected to $\mathrm{m}^{6} \mathrm{~A}-\mathrm{IP}$. The $P$ value (Student's $t$-test) is ${ }^{\star \star \star \star} P=5.09 \times 10^{-9}$. j Fold increase in $\mathrm{m}^{6} \mathrm{~A}$ content in viral RNA compared to controls. The $P$ value (Student's $t$-test) is ${ }^{\star \star \star \star} P=2.57 \times 10^{-6}$. Results are from three or four independent experiments

proteins (METTL3 and METTL14) and eraser protein (ALKBH5) were distributed in the nucleus although a small fraction of these proteins was also found in the cytoplasm (Fig. 6b and Supplementary Figs. 10 and 11). Also, viral N protein was partially colocalized with writer protein (METTL3) (Fig. 6b). Another eraser protein, FTO, was exclusively located in the nucleus (Fig. 6c). Equal amounts of $\mathrm{m}^{6} \mathrm{~A}$ related proteins were detected in the cytoplasmic and nuclear fractions by Western blot (Fig. 6d, e). Therefore, RSV infection does not significantly alter the distribution pattern of $\mathrm{m}^{6} \mathrm{~A}$-related proteins in HeLa cells.

$m^{6} A$ reader proteins bind to both $R S V$ genomic $R N A$ and mRNA. Since the biological function of $\mathrm{m}^{6} \mathrm{~A}$ is mediated by $\mathrm{m}^{6} \mathrm{~A}$ binding proteins, we next determined whether YTHDF2 can directly bind to RSV RNAs in virus-infected cells. As expected, YTHDF2 was pulled down by YTHDF2-specific antibody (Supplementary Fig. 12A). Both RSV genomic RNA and N mRNA were efficiently precipitated as complexes, with YTHDF2 (Supplementary Fig. 12B). We further confirmed this result by pulling down HA-tagged YTHDF2 from total cell lysates of HeLa cells overexpressing YTHDF2 with HA antibody (Supplementary Fig. 12C). Similarly, significant amounts of RSV genomic RNA and $\mathrm{N}$ mRNA bound to YTHDF2 (Supplementary Fig. 12D). Since $G$ mRNA has the strongest $\mathrm{m}^{6} \mathrm{~A}$ enrichment, we also determined the binding of $\mathrm{m}^{6} \mathrm{~A}$ reader proteins to $\mathrm{G}$ mRNA. All reader proteins (YTHDF1, 2, and 3) were capable of binding to $G$ mRNA (Supplementary Fig. 12E).

Abrogation of $\mathbf{m}^{\mathbf{6}} \mathrm{A}$ sites results in attenuation of RSV. Based on $\mathrm{m}^{6} \mathrm{~A}$-seq, $\mathrm{G}$ gene and $\mathrm{G}$ mRNA have the most abundant $\mathrm{m}^{6} \mathrm{~A}$ enrichment in both HeLa and A549 cells (Fig. 1). Thus, we decided to mutate the $\mathrm{m}^{6} \mathrm{~A}$ sites in the $G$ gene region which we found to be conserved in the $\mathrm{m}^{6} \mathrm{~A}$-seq from both HeLa and A549 cells (Supplementary Fig. 13). These mutations were predicted to remove the $\mathrm{m}^{6} \mathrm{~A}$ sites in the $\mathrm{G} \mathrm{mRNA}$ and in the $G$ gene region of the antigenome without changing the amino acid they encoded. Recombinant RSVs carrying these mutations were recovered by reverse genetics system. First, the potential $\mathrm{m}^{6} \mathrm{~A}$ sites in regions 1 , 

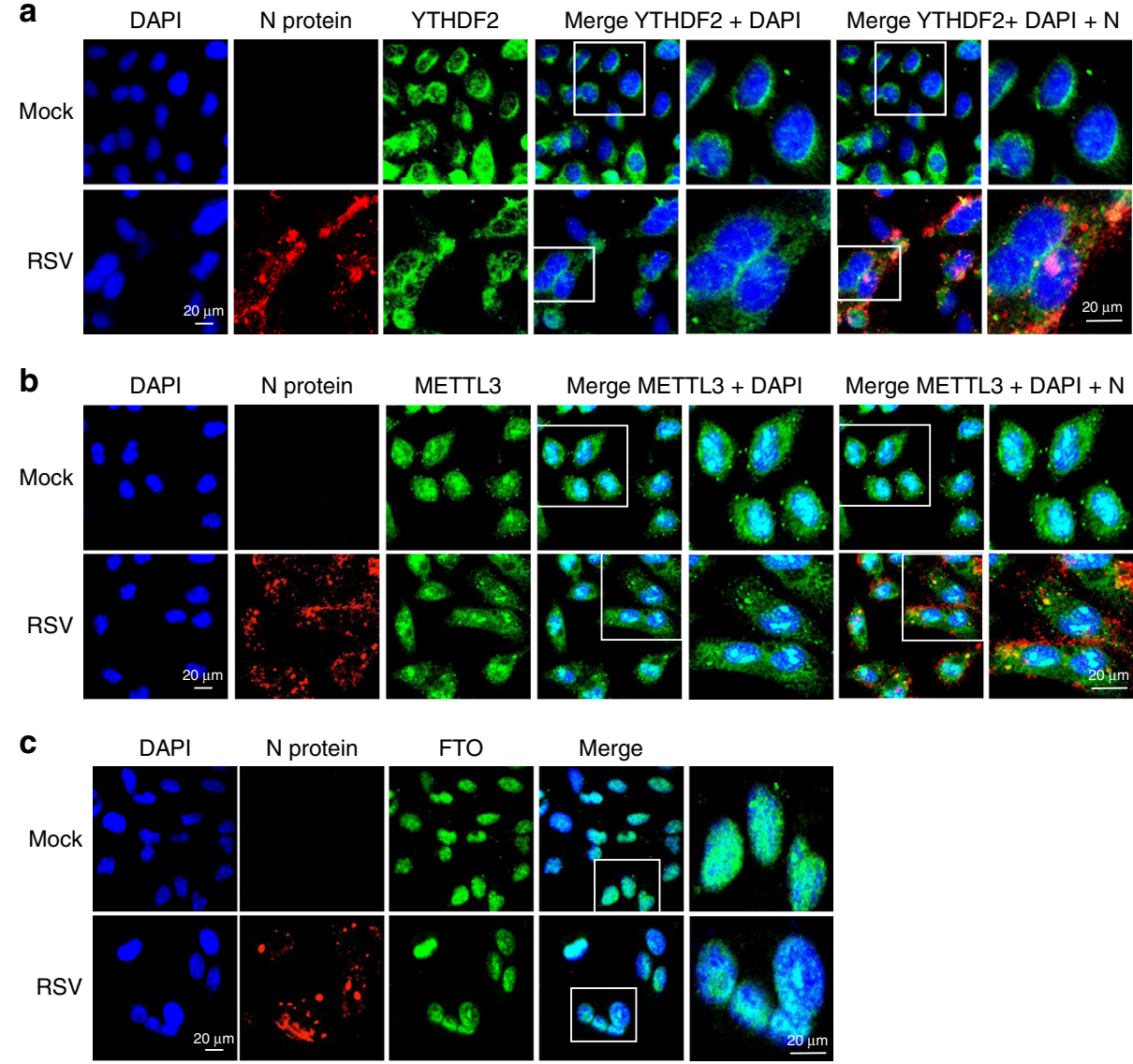

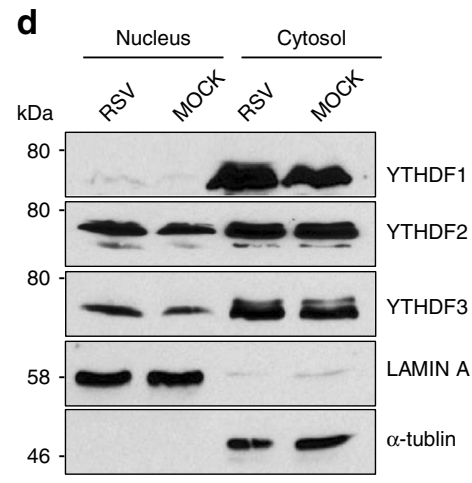

Fig. 6 RSV infection does not alter the $\mathrm{m}^{6} \mathrm{~A}$ reader, writer, or eraser protein distribution in cells. HeLa cells were infected by rgRSV at an MOI of 10.0 . At $24 \mathrm{~h}$ post-infection, mock- or rgRSV-infected cells were stained with anti-reader, writer, or eraser protein antibody (green) and anti-RSV $\mathrm{N}$ protein antibody (red), and were analyzed by confocal microscope. Nuclei were labeled with DAPI (blue). Micrographs with $\times 60$ magnification (scale bar of $20 \mu m$ ) are shown. a $\mathrm{m}^{6} \mathrm{~A}$ reader protein YTHDF2; b $\mathrm{m}^{6} \mathrm{~A}$ writer protein METTL3; and $\mathbf{c} \mathrm{m}^{6} \mathrm{~A}$ eraser protein FTO. d Detection of $\mathrm{m}^{6} \mathrm{~A}$ reader, writer, and eraser proteins by Western blot. Nuclear and cytoplasmic fractions were separated from mock- or rgRSV-infected HeLa cells, and were subjected to western blot. Nuclear and cytoplasmic markers were indicated by Lamin $A$ and $\alpha$-Tubulin, respectively. Representative results from three independent experiments are shown

2, and 3 were mutated individually to produce rgRSV-G1, G2, and G3, respectively. Second, mutations of $\mathrm{m}^{6} \mathrm{~A}$ sites in regions 1 and 2 were combined to produce rgRSV-G12. Third, $\mathrm{m}^{6} \mathrm{~A}$ sites in regions 1, 2, and 3 were combined to produce rgRSV-G123. All $\mathrm{m}^{6} \mathrm{~A}$-mutated rgRSVs had various degrees of reduction in viral $\mathrm{F}$ and $G$ protein synthesis in A549 cells compared to the parental rgRSV (Fig. 7a). Significantly less GFP expression was observed in $\mathrm{m}^{6} \mathrm{~A}$-mutated rgRSVs compared to rgRSV at $48 \mathrm{~h}$ post-infection (Fig. 7b, c, and Supplementary Fig. 14). Single-step growth curves showed that $\mathrm{m}^{6} \mathrm{~A}$-mutated rgRSVs had delayed replication kinetics and had $0.5-1.5 \log$ reductions in peak titer compared to rgRSV (Fig. 7d). Overall, mutants rgRSV-G1, G3, G12, and G123 had a moderate defect whereas rgRSV-G2 had a mild defect in replication. Real-time RT-PCR results showed that both rgRSVG1 and G12 had defects in genome (Fig. 7e), NS1 (Fig. 7f), and G (Fig. 7g) mRNA synthesis compared to rgRSV, and rgRSV-G1 had more defects than rgRSV-G12. Next, we calculated the percentage of reduction for NS1 and G mRNA. It was found that NS1 mRNA had significantly less reduction than G mRNA, suggesting that removal of the $\mathrm{m}^{6} \mathrm{~A}$ from the $\mathrm{G}$ mRNA may accelerate its decay.

$\mathrm{m}^{6} \mathrm{~A}$-mutated rgRSVs are defective in replication in HAE. We next tested the replication and spread of $\mathrm{m}^{6} \mathrm{~A}$-deficient rgRSVs in HAE cultures, a near in vivo model for lower airway infection.
These cultures are pseudostratified and polarized, closely resembling the in vivo airway epithelium morphology and function, including mucus production and ciliary motion ${ }^{47}$. In brief, HAE cultures were infected with $800 \mathrm{TCID}_{50}$ of each recombinant virus, and viral release and spread was monitored. As in A549 cells, $\mathrm{m}^{6} \mathrm{~A}$-mutated rgRSVs had a delay in viral gene expression (GFP production) and spread (Fig. 8a, b). At day 4 post-inoculation, $\mathrm{m}^{6} \mathrm{~A}$-mutated rgRSVs had fewer green cells compared to rgRSV. Although several rgRSV mutants gradually increased at days 6 and 8, the density of green cells remained less than for rgRSV. rgRSV-G1 was delayed in spreading but eventually spread to most susceptible cells at day 8 . rgRSV-G2 had a delay at the early time point (day 4) but had wild-type level of spreading at later times. Recombinant rgRSV-G12 was the most defective virus in HAE cultures, displaying a weak GFP signal during the entire experimental period. In addition, $\mathrm{m}^{6} \mathrm{~A}$-mutated $\mathrm{rgRSV}$ had delays in virus release in HAE culture with 1-2 log defects in virus yield (Fig. 8c). These results demonstrate that $\mathrm{m}^{6} \mathrm{~A}$-mutated rgRSVs were defective in replication and spread in this near in vivo lung infection model.

$\mathrm{m}^{6} \mathrm{~A}$-mutated rgRSVs are defective in replication in vivo. We tested replication and pathogenesis of four $\mathrm{m}^{6} \mathrm{~A}$-mutated $\mathrm{rgRSV}$ mutants, rgRSV-G1, G2, G3, and G12, in cotton rats. The parental rgRSV replicated efficiently in the lungs (Fig. 9a) and nasal 
a
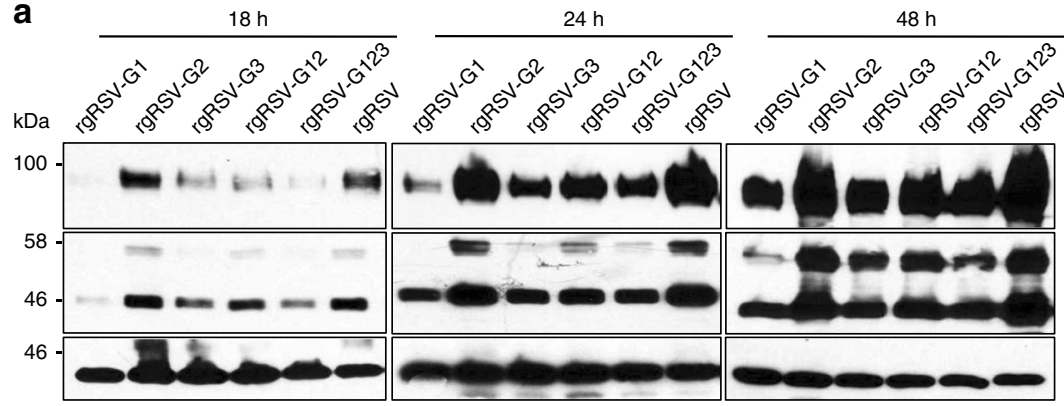

b
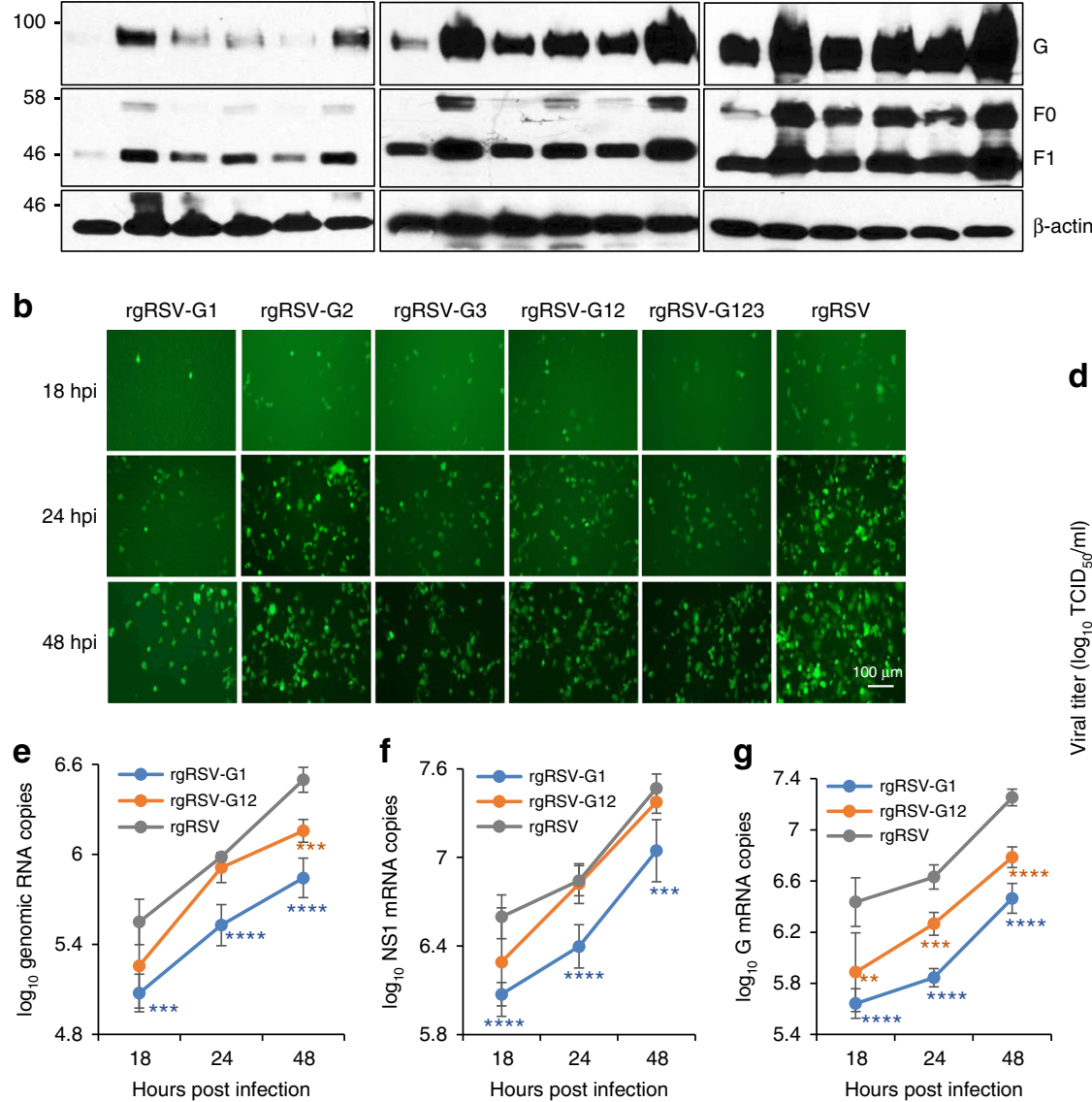

C

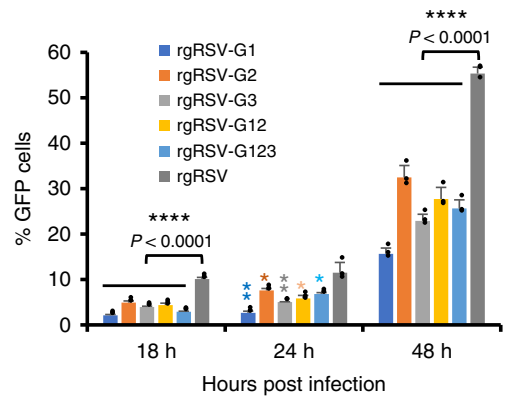

Fig. $7 \mathrm{~m}^{6} \mathrm{~A}$-abrogating RSV mutants have defects in replication in immortalized cells. a Immunoblot analysis of RSV proteins. Confluent A549 cells were infected with each rgRSV at an $\mathrm{MOI}$ of 0.1 , cell lysates were harvested at 18,24 , and $48 \mathrm{~h}$ post-infection, and RSV proteins were detected by specific antibodies against $\mathrm{F}$ and $\mathrm{G}$ protein. $\mathbf{b}$ GFP expression of $\mathrm{m}^{6} \mathrm{~A}$-deficient rgRSV mutants. Micrographs with $\times 10$ magnification (scale bar of $100 \mu \mathrm{m}$ ) are shown. c Quantification of GFP-positive cells by flow cytometry. The $P$ value (Student's t-test) for rgRSV-G1, G2, G3, G12, and G123 at $18 \mathrm{~h}$ post-inoculation is ${ }^{\star \star \star \star} P=5.87 \times 10^{-6},{ }^{\star \star \star \star \star} P=7.13 \times 10^{-5},{ }^{\star \star \star \star} P=1.65 \times 10^{-5},{ }^{\star \star \star \star} P=6.49 \times 10^{-5}$, and ${ }^{\star \star \star \star} P=6.98 \times 10^{-6}$, respectively; at $24 \mathrm{~h}$ post-inoculation is ${ }^{\star \star} P=$ $0.00261,{ }^{\star} P=0.0418,{ }^{\star \star} P=0.00766,{ }^{\star} P=0.0138$, and ${ }^{\star} P=0.0230$ respectively; at 48 h post-inoculation is ${ }^{\star \star \star \star} P=3.55 \times 10^{-6},{ }^{\star \star \star \star} P=1.82 \times$ $10^{-4},{ }^{\star \star \star \star} P=9.83 \times 10^{-6},{ }^{\star \star \star \star} P=7.78 \times 10^{-5}$, and ${ }^{\star \star \star \star} P=2.48 \times 10^{-5}$, respectively. d Single-step growth curve of $\mathrm{m}^{6} \mathrm{~A}-\mathrm{deficient}$ rgRSV mutants in A549 cells. Confluent A549 cells were infected with each rgRSV at an $\mathrm{MOI}$ of 1.0, supernatants were harvested, and viral titer was determined by $\mathrm{TCID}_{50}$ assay. e RSV genomic RNA replication. At 18, 24, and $48 \mathrm{~h}$ post-infection, total RNA was purified from rgRSV-infected cells using TRizol, and genomic RNA was quantified by real-time RT-PCR using specific primers annealing to the RSV leader sequence and GFP gene. The $P$ value (Student's $t$-test) for rgRSV-G1 at 18,24 , and $48 \mathrm{~h}$ is ${ }^{\star \star \star} P=0.000653{ }^{* \star * \star} P=8.66 \times 10^{-5}$, and ${ }^{\star \star \star \star} P=1.33 \times 10^{-5}$ respectively. The $P$ value for rgRSV-G12 at $48 \mathrm{~h}$ is ${ }^{\star \star \star} P=0.000141 . \mathbf{f}$ RSV NS1 mRNA transcription. Viral mRNA was separated from total RNA and quantified by real-time PCR using primers annealing to the NS1. The $P$ value (Student's $t$-test) for rgRSV-G1 at 18,24 , and $48 \mathrm{~h}$ is ${ }^{\star \star \star \star} P=1.80 \times 10^{-5},{ }^{\star \star \star \star} P=1.11 \times 10^{-4}$, and ${ }^{\star \star \star} P=0.001$, respectively. $\mathrm{g}$ RSV G mRNA transcription. The $P$ value (Student's $t$-test) for rgRSV-G1 at 18,24 , and $48 \mathrm{~h}$ is ${ }^{\star \star \star \star} P=7.13 \times 10^{-5}$, ${ }^{\star \star \star \star} P=5.10 \times 10^{-6}$, and ${ }^{\star \star \star \star} P=1.22 \times 10^{-6}$, respectively. The $P$ value (Student's $t$-test) for rgRSV-G12 at 18,24 , and $48 \mathrm{~h}$ is ${ }^{\star \star} P=0.00942,{ }^{\star \star \star} P=0.000199$, and ${ }^{\star \star \star \star} P=1.35 \times 10^{-5}$, respectively. Results are from three independent experiments. Flow cytometry data are expressed as mean \pm standard deviation. RNA copy and viral titer are the geometric mean titer (GMT) of three independent experiments \pm standard deviation. Western blots shown are the representatives of three independent experiments

turbinates (Fig. 9b) with average viral titers of $4.70 \pm 0.10 \log _{10}$ $\mathrm{TCID}_{50} / \mathrm{g}$ and $4.10 \pm 0.10 \log _{10} \mathrm{TCID}_{50} / \mathrm{g}$, respectively. Mutant rgRSV-G1 had a 7-fold reduction in replication in nasal turbinate and lung titers, respectively $(P<0.05)$. Mutant rgRSV-G2 had no significant reduction in replication in lung $(P>0.05)$ but 3 -fold reduction in nasal turbinate $(P<0.05)$. Mutant rgRSV-G12 had the most dramatic defect in replication, with reductions of 100 and 200 -fold in viral titer in nasal turbinate and lung, respectively. It should be noted that 4 out of 5 cotton rats had below detection limit level of RSV replication in the nasal turbinate and 3 out of 5 cotton rats had below detection limit level of RSV replication in lungs, suggesting that rgRSV-G12 is highly attenuated in vivo. The rgRSV-G3 had 5-fold reduction in replication in nasal turbinate and lung $(P<0.05)$. Histologic examination showed that rgRSV caused moderate pulmonary histopathological changes, including interstitial pneumonia and peribronchial lymphoplasmocytic infiltrates (Fig. 9c). In contrast, $\mathrm{m}^{6} \mathrm{~A}$-deficient rgRSV mutants only had mild and less pulmonary histopathological changes compared to rgRSV (Fig. 9c). These results showed that $\mathrm{m}^{6} \mathrm{~A}$-deficient rgRSV mutants had significant reductions in viral replication in both the upper and lower respiratory tracts in cotton rats and were less pathogenic 
a

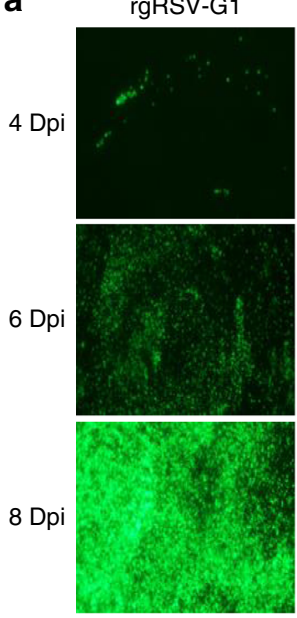

rgRSV-G2
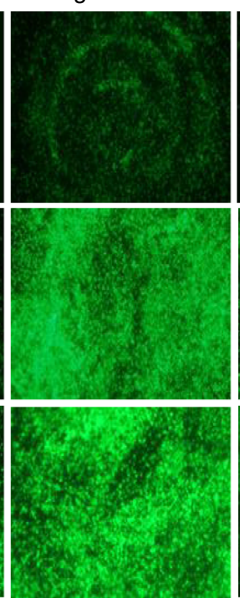

rgRSV-G3

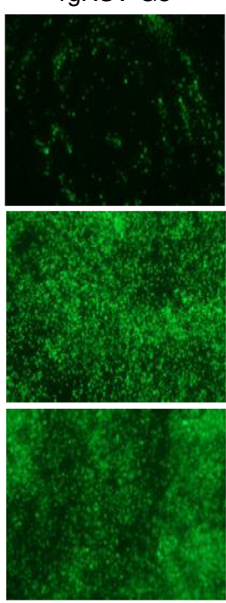

rgRSV-G12

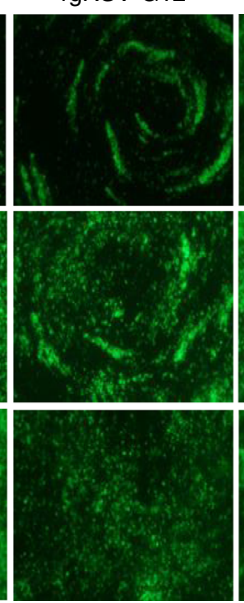

rgRSV-G123

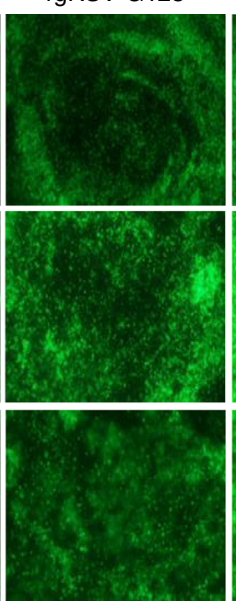

rgRSV

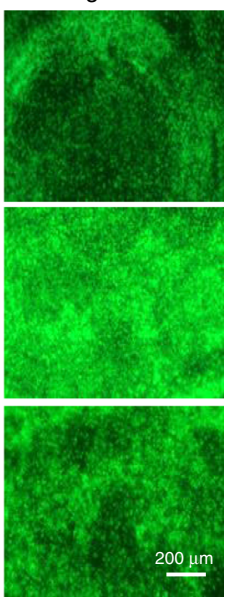

b
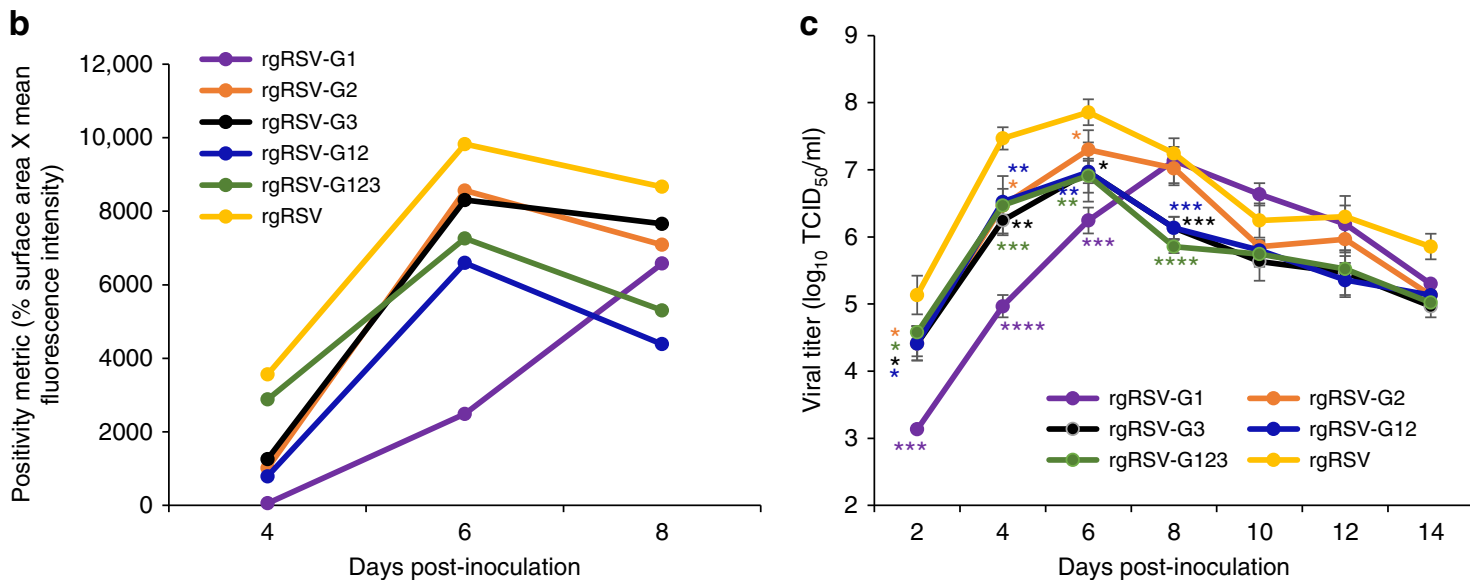

Fig. $8 \mathrm{~m}^{6} \mathrm{~A}$-abrogating RSV mutants have defects in replication in HAE culture. a Spreading of $\mathrm{m}^{6} \mathrm{~A}$ mutated rgRSVs in HAE culture. HAE cultures were infected by $800 \mathrm{TCI}_{50}$ of each rgRSV. At the indicated time, virus spreading was monitored by fluorescence microscopy. Representative micrographs with $\times 4$ magnification (scale bar of $200 \mu \mathrm{m}$ ) at each time point are shown. $\mathbf{b}$ Quantification of GFP signal in HAE culture. GFP signal was quantified by Image J software, and data are expressed as mean of three transwells of HAE culture, and are the representatives of three independent experiments. c Virus release from $\mathrm{m}^{6} \mathrm{~A}$ mutated rgRSV-infected HAE culture. HAE cultures were infected by $800 \mathrm{TCID}_{50}$ of each rgRSV. After virus inoculation, supernatants were collected every 2 days until day 14 post-inoculation. Infectious virus in supernatants was determined by $T_{C}$ ID $_{50}$ assay. Viral titers are the geometric mean titer (GMT) of three independent experiments \pm standard deviation. The $P$ value (Student's $t$-test) for rgRSV-G1 at days 2,4 , and 6 is ${ }^{\star \star \star} P=0.000277,{ }^{\star \star \star \star} P=5.15 \times 10^{-5}$, and ${ }^{\star \star \star} P=0.000513$, respectively; for rgRSV-G2 at days 2,4 , and 6 is ${ }^{\star} P=0.0315,{ }^{\star} P=0.0213$, and ${ }^{\star} P=0.0504$, respectively; for rgRSV-G3 at days $2,4,6$, and 8 is ${ }^{\star} P=0.0315,{ }^{\star \star} P=0.00115,{ }^{\star} P=0.0330$, and ${ }^{\star \star \star} P=0.000565$ respectively; for rgRSV-G12 at days 2,4 , 6 , and 8 is ${ }^{\star} P=0.0227,{ }^{\star \star} P=0.00302,{ }^{\star \star} P=0.00375$, and ${ }^{\star \star \star} P=0.000565$ respectively; for rgRSV-G123 at days $2,4,6$, and 8 is ${ }^{\star} P=0.0342,{ }^{\star \star \star} P=$ $0.000486,{ }^{\star \star} P=0.00682$, and ${ }^{\star \star \star *} P=6.07 \times 10^{-5}$ respectively

compared to rgRSV. These results indicate that viral $\mathrm{m}^{6} \mathrm{~A}$ upregulates viral replication and pathogenesis in vivo.

$\mathrm{m}^{6} \mathrm{~A}$-mutated rgRSVs are highly immunogenic in cotton rats. To determine whether defects in viral $\mathrm{m}^{6} \mathrm{~A}$ methylation impair the immunogenicity of the virus, we evaluated the protection efficacy of a partially attenuated (rgRSV-G1) and highly attenuated (rgRSV-G12) virus in cotton rats. Cotton rats immunized with parental rgRSV or $\mathrm{m}^{6} \mathrm{~A}$-mutated rgRSVs did not have any detectable infectious virus in either the nasal turbinate or lung tissue after challenge with rgRSV (Fig. 9d). In contrast, unvaccinated challenged controls had average titers of $5.12 \pm 0.28$ and $4.27 \pm 0.07 \log _{10} \mathrm{PFU} / \mathrm{g}$ in the lung and nasal turbinate, respectively (Fig. 9d). These results demonstrate that immunization with the rgRSV-G1 and G12 provided complete protection from challenge with rgRSV. Lung histology showed that unvaccinated challenged controls had moderate histologic lesions (Supplementary Fig. 15). However, the vaccinated challenged groups had only mild lesions in lungs. In addition, no enhanced lung damage was observed (Supplementary Fig. 15). The most attenuated $\mathrm{m}^{6} \mathrm{~A}$ deficient virus (rgRSV-G12) triggered similar levels of neutralizing antibody compared to rgRSV $(P>0.05)$ (Fig. 9e). The rgRSVG1 had a lower antibody titer at week 3 and 4 compared to rgRSV (Fig. 9e). These results demonstrate that $\mathrm{m}^{6} \mathrm{~A}$-mutated rgRSV retained high immunogenicity and provided complete protection against RSV infection in cotton rats.

$\mathrm{m}^{6} \mathrm{~A}$-mutated rgRSVs are less dependent on host $\mathrm{m}^{\mathbf{6}} \mathrm{A}$ machinery. If the attenuated phenotype of $\mathrm{m}^{6} \mathrm{~A}$-mutated rgRSVs is indeed $\mathrm{m}^{6} \mathrm{~A}$-dependent, alteration of host $\mathrm{m}^{6} \mathrm{~A}$ machinery would have no or less of an impact on replication and gene expression. To address this question, we tested the replication of rgRSV-G1 and G12 in A549 cells overexpressing ALKBH5 which is an $\mathrm{m}^{6} \mathrm{~A}$ eraser protein. Overexpression of ALKBH5 led to $70 \%$ and $42 \%$ reduction in RSV G and F protein synthesis in rgRSVinfected cells compared to vector control cells (Fig. 10a). We also 
a

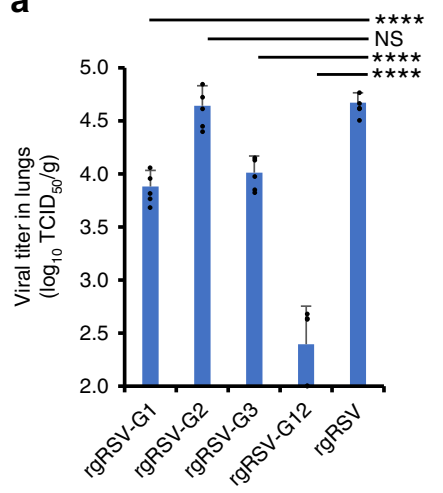

b

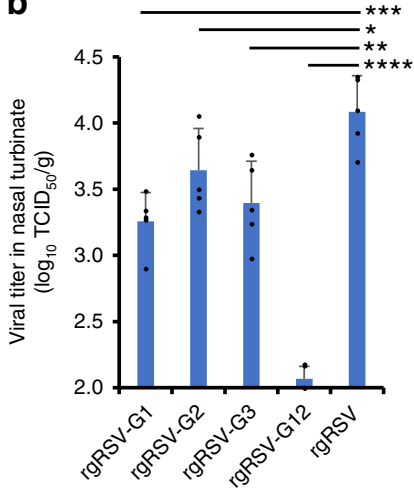

d

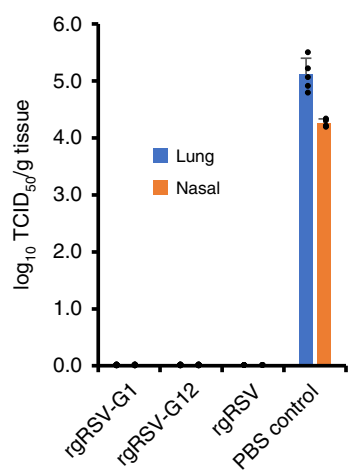

e

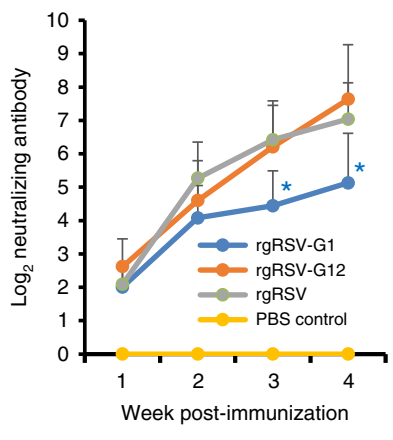

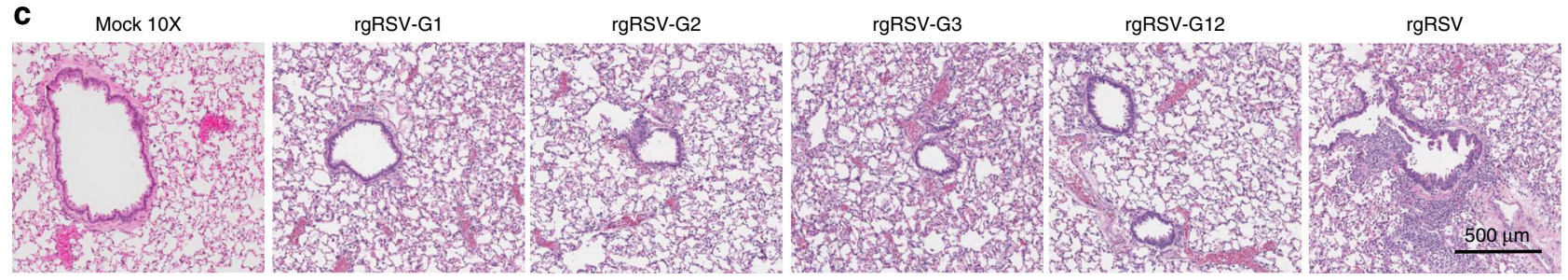

Fig. 9 Pathogenicity and immunogenicity of $\mathrm{m}^{6} \mathrm{~A}$-mutated rgRSVs in cotton rats. a RSV titer in lungs. Four-week-old SPF cotton rats were inoculated intranasally with $2.0 \times 10^{5} \mathrm{TCID}_{50}$ of each rgRSV. At day 4 post-infection, the cotton rats were killed, and lungs and nasal turbinates were collected for virus titration by $\mathrm{TCID}_{50}$ assay. Viral titers are the geometric mean titer (GMT) of 5 animals \pm standard deviation. Detection limit is $2.0 \mathrm{log} T C I D_{50} / g$ tissue. The $P$ value (Student's $t$-test) for rgRSV-G1, rgRSV-G3, and rgRSV-G12 is ${ }^{\star \star \star \star} P=9.99 \times 10^{-6},{ }^{\star \star \star \star \star} P=4.06 \times 10^{-5}$, and ${ }^{\star \star \star \star \star} P=7.89 \times 10^{-7}$ respectively. b RSV titer in nasal turbinates. The $P$ value (Student's $t$-test) for rgRSV-G1, rgRSV-G2, rgRSV-G3, and rgRSV-G12 is ${ }^{\star \star \star} P=0.000740,{ }^{\star} P=$ $0.0460,{ }^{\star \star} P=0.00623$, and ${ }^{\star \star \star \star} P=2.88 \times 10^{-7}$ respectively. $\mathbf{c ~} \mathrm{m}^{6} \mathrm{~A}$ mutated rgRSVs had less lung histopathological changes compared to rgRSV. Representative pathological changes from each group are shown. Right lung lobe of each cotton rat was fixed in $4 \%$ neutral buffered formaldehyde, embedded in paraffin, sectioned at $5 \mu \mathrm{m}$, and stained with hematoxylin-eosin (HE) for the examination of histological changes by light microscopy. Micrographs with $\times 20$ magnification (scale bar of $500 \mu \mathrm{m}$ ) are shown. $\mathbf{d} \mathrm{m}^{6} \mathrm{~A}$ mutated rgRSV provides complete protection against RSV challenge. Fourweek-old SPF cotton rats were inoculated intranasally with $2.0 \times 10^{5} \mathrm{TCID}_{50}$ of each rgRSV. At week 4 post-immunization, cotton rats were challenged with $2.0 \times 10^{5} \mathrm{TCID}_{50} \mathrm{rgRSV}$. At day 4 post-challenge, the cotton rats were killed, and lungs and nasal turbinates were collected for virus titration by $\mathrm{TCID}_{50}$ assay. Viral titers are the geometric mean titer (GMT) of 5 animals \pm standard deviation. The detection limit is 2.0 log TCID $50 / g$ tissue. e rgRSV induced a high level of neutralizing antibody. Blood samples were collected from each rat weekly by retro-orbital bleeding. The RSV-neutralizing antibody titer was determined using a plaque reduction neutralization assay, as described in Materials and Methods. The $P$ value (Student's $t$-test) for rgRSV-G1 at week 3 and 4 is ${ }^{*} P=0.0166$ and ${ }^{\star} P=0.0490$, respectively

observed a reduction in replication and protein expression of the $\mathrm{m}^{6} \mathrm{~A}$-mutated rgRSVs in ALKBH5 overexpressing cells, but the level of reduction was much less compared to the parental rgRSV. For example, only $17 \%$ and $10 \%$ reduction in RSV G and $\mathrm{F}$ protein synthesis was observed for rgRSV-G12, and 50\% and 20\% reduction in $G$ and $F$ protein was observed for rgRSV-G1, respectively. We also tested the replication of rgRSV-G123 in $\mathrm{m}^{6} \mathrm{~A}$ writer protein-depleted A549 cells. Knockdown of MELL3 and METTL14 led to 32 and $22 \%$ reduction in RSV G and F protein in rgRSV-infected A549 cells whereas only 25\% and 8\% reduction in $G$ and $F$ in rgRSV-G123-infected A549 cells (Fig. 10b). Thus, these results showed that replication and gene expression of $\mathrm{m}^{6} \mathrm{~A}$-mutated rgRSVs were less dependent on host $\mathrm{m}^{6} \mathrm{~A}$ machinery, suggesting that the attenuated phenotype of these mutants is likely due to the deficiency in $\mathrm{m}^{6} \mathrm{~A}$ methylation of the viral RNA.

$\mathrm{m}^{\mathbf{6}} \mathrm{A}$-mutated rgRSVs are deficient in $\mathbf{m}^{\mathbf{6}} \mathrm{A}$ enrichment. To determine whether $\mathrm{m}^{6} \mathrm{~A}$ sites are indeed missing from the $\mathrm{G}$ gene, A549 cells were infected by each $\mathrm{m}^{6} \mathrm{~A}$-mutated $\mathrm{rgRSV}$, and polyadenylated mRNAs were isolated and subjected to $\mathrm{m}^{6} \mathrm{~A}$-seq. As shown in Fig. 10c and Supplementary Fig. 16, the enrichment of $\mathrm{m}^{6} \mathrm{~A}$ in the $\mathrm{G}$ mRNA of each $\mathrm{m}^{6} \mathrm{~A}$-mutated rgRSV significantly decreased compared to the G mRNA from the parental rgRSV, confirming that $\mathrm{m}^{6} \mathrm{~A}$ methylation in the $\mathrm{G}$ mRNA has indeed been significantly reduced. Our mutagenesis targeted the positive- sense RNA which includes both antigenome and G mRNA. To determine whether antigenome is also defective in $\mathrm{m}^{6} \mathrm{~A}$ methylation, virion RNA was extracted from highly purified virions of rgRSV, rgRSV-G12, rgRSV-G123, and rgRSV- $\Delta \mathrm{G}$ (rgRSV with deletion of entire $\mathrm{G}$ gene), and $\mathrm{m}^{6} \mathrm{~A}$ content in total RNA was measured. As shown in Fig.10d, $\mathrm{m}^{6} \mathrm{~A}$ content in virion RNA of rgRSV-G12, rgRSV-G123, and rgRSV- $\Delta$ G was significantly less compared to those in $\operatorname{rgRSV}(P<0.05)$. In addition, there was no significant difference in $\mathrm{m}^{6} \mathrm{~A}$ content between $\mathrm{rgRSV}-\mathrm{G} 123$, and rgRSV- $\Delta \mathrm{G}(P>0.05)$. Collectively, these results demonstrate that $\mathrm{m}^{6} \mathrm{~A}$-mutated rgRSVs indeed have defects in $\mathrm{m}^{6} \mathrm{~A}$ methylation.

\section{Discussion}

The biological function of $\mathrm{m}^{6} \mathrm{~A}$ methylation in viral RNAs has remained uncertain since its discovery 40 years ago. Recent studies have shown that viral $\mathrm{m}^{6} \mathrm{~A}$ methylation can have pro-viral or antiviral functions dependent on the specific virus species and cell type. Here, we showed that $\mathrm{m}^{6} \mathrm{~A}$ modification positively regulates each step in the RSV replication cycle ranging from genome replication, mRNA transcription, and viral protein synthesis, to progeny infectious particle production. We demonstrated that $\mathrm{m}^{6} \mathrm{~A}$ regulates RSV replication and pathogenesis in an animal model. Furthermore, we provide evidence that $\mathrm{m}^{6} \mathrm{~A}$ could be a target for the development of live attenuated vaccine candidates.

The $\mathrm{m}^{6} \mathrm{~A}$ methylation of RNAs is modulated by writers, erasers, and readers in host cells. It should be noted that $\mathrm{m}^{6} \mathrm{~A}$ 

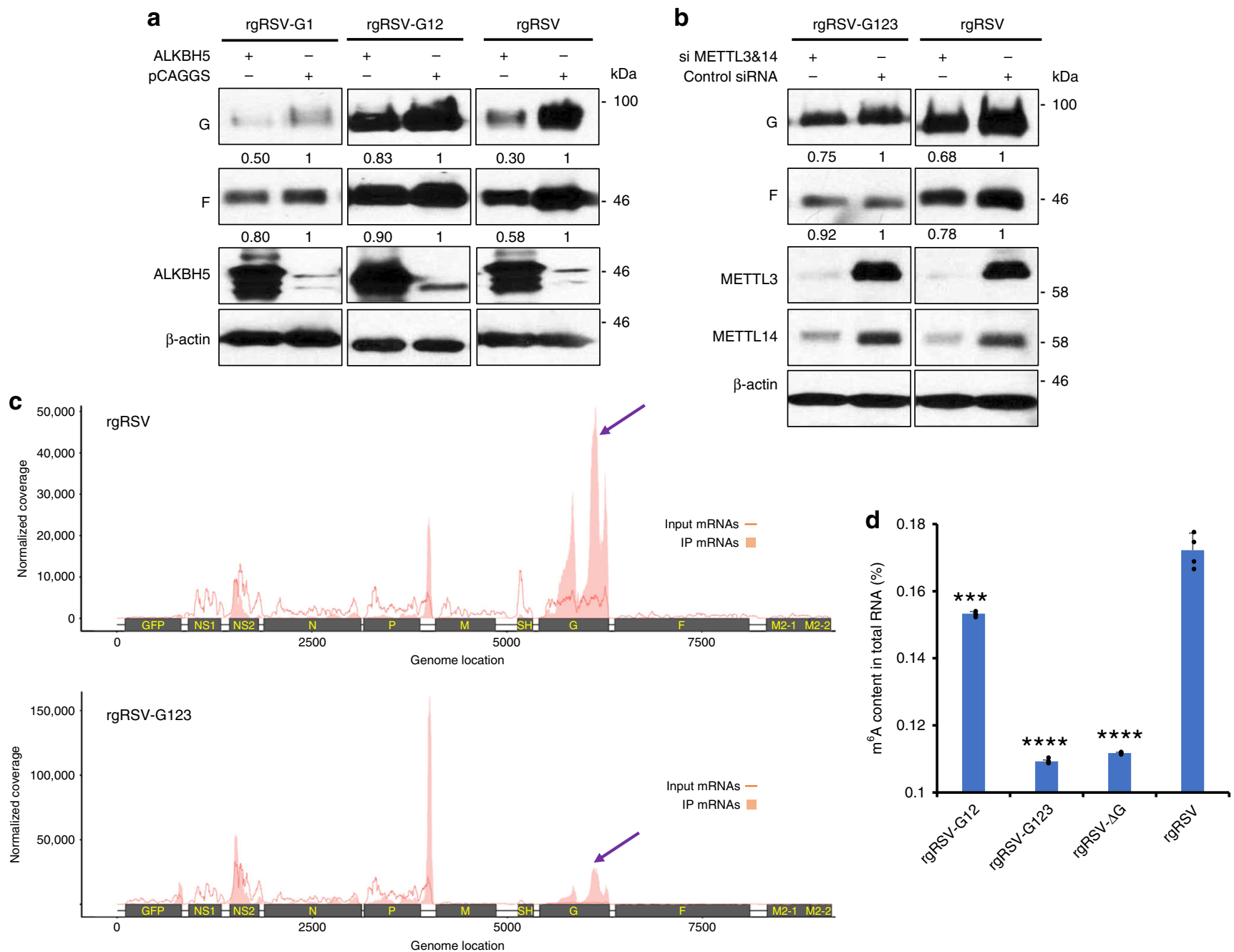

Fig. 10 The attenuated phenotype of $m^{6} \mathrm{~A}$ mutated rgRSVs is $\mathrm{m}^{6} \mathrm{~A}$-related. a rgRSV-G1 and $-\mathrm{G} 12$ were less dependent on the $\mathrm{m}^{6} \mathrm{~A}$ eraser protein. $\mathrm{A} 549$ cells were transfected with a plasmid encoding ALKBH5. At $36 \mathrm{~h}$ post-transfection, cells were infected with each rgRSV at an MOI of 0.5 . At $18 \mathrm{~h}$ postinfection, cell lysates were harvested for western blot analysis. Western blot images are the representatives of three experiments. $\mathbf{b}$ rgRSV-G123 expression was less dependent on $\mathrm{m}^{6} \mathrm{~A}$ writer protein. A549 cells were transfected with control siRNA or siRNA targeting METTL3 and METTL14. At $36 \mathrm{~h}$ post-transfection, cells were infected with each rgRSV at an $\mathrm{MOI}$ of 0.5 . At $18 \mathrm{~h}$ post-infection, cell lysates were harvested for western blot analysis. The density of western blot was quantified by Image J software, and the ratio of the protein bands was calculated. Images are the representatives of three experiments. c Distribution of $\mathrm{m}^{6} \mathrm{~A}$ peaks on the RSV mRNAs from A549 cells infected by rgRSV and rgRSV-G123. Confluent A549 cells were infected by each $\mathrm{m}^{6} \mathrm{~A}$-mutated rgRSV at an $\mathrm{MOI}$ of 1.0 , cell lysates were harvested at $36 \mathrm{~h}$ post-infection. Total RNAs were extracted from cell lysates, and were enriched for mRNA by binding to oligo dT, and subjected to $\mathrm{m}^{6} \mathrm{~A}$-seq. The distribution of $\mathrm{m}^{6} \mathrm{~A}$-immunoprecipitated (IP) reads were mapped to the RSV mRNAs (pink block). The baseline distributions for mRNAs from input sample are shown as a pink line. Data presented are the mean coverage from two independent virus-infected A549 cell samples $(n=2)$. Red arrow indicates the $m^{6} \mathrm{~A}$ enrichment in $\mathrm{G}$ mRNA. d Virion RNA of m ${ }^{6} \mathrm{~A}-\mathrm{mutated}$ rgRSVs is defective in binding to anti- $\mathrm{m}^{6} \mathrm{~A}$ antibody. Virion RNA was extracted from highly purified RSV virions. Antigenome was quantified by real-time RT-PCR. Each amount of antigenome was bound to strip wells using a RNA high binding solution, and $\mathrm{m}^{6} \mathrm{~A}$ was detected using a specific capture anti-m ${ }^{6} \mathrm{~A}$ antibody and then quantified colorimetrically by reading the absorbance in a microplate spectrophotometer at a wavelength of $450 \mathrm{~nm}$. A standard curve was generated using known $\mathrm{m}^{6} \mathrm{~A}$ methylated RNA (range from 0.02 to $1 \mathrm{ng}$ of $\mathrm{m}^{6} \mathrm{~A}$ ) as a positive control. The $\mathrm{m}^{6} \mathrm{~A}$ content was calculated from each RNA samples. Data are averages of four independent experiments. The $P$ value (Student's $t$-test) for rgRSV-G12, rgRSV-G123, and rgRSV- $\Delta \mathrm{G}$ is ${ }^{\star \star \star} P=$ $0.000325,{ }^{\star \star \star \star} P=3.09 \times 10^{-7}$, and ${ }^{\star \star \star \star} P=3.74 \times 10^{-7}$, respectively

methylation and its reader proteins may play distinct roles in a virus life cycle. In this study, we showed that overexpression of both $\mathrm{m}^{6} \mathrm{~A}$ reader and writer proteins positively regulated RSV replication while knockdown inhibited RSV gene expression and replication. The opposite was true for eraser proteins: overexpression decreased RSV gene expression and replication whereas knockdown increased them. In case of influenza virus, $\mathrm{m}^{6} \mathrm{~A}$ methylation enhanced viral replication as did the reader, YTHDF2, but not YTHDF1 or $3^{33}$. We found that overexpression of $\mathrm{m}^{6} \mathrm{~A}$ writer proteins led to an increased level of $\mathrm{m}^{6} \mathrm{~A}$ in viral RNA. The impact of $\mathrm{m}^{6} \mathrm{~A}$-related proteins on RSV replication may result from three aspects: a change in $\mathrm{m}^{6} \mathrm{~A}$ levels in viral RNA which directly affects viral replication, a change in host gene expression which indirectly affect viral replication, or both. However, $\mathrm{m}^{6} \mathrm{~A}$ writer and $\mathrm{m}^{6} \mathrm{~A}$ reader proteins have been found to negatively regulate $\mathrm{HCV}$ production ${ }^{38}$, opposite to RSV and influenza virus. In addition, the role of $\mathrm{m}^{6} \mathrm{~A}$ reader proteins in the HIV life cycle is controversial ${ }^{30-32}$. Thus, $\mathrm{m}^{6} \mathrm{~A}$ readers have distinct effects on the life cycles of different viruses, as they are multifunctional and play many important biological 
roles ranging from RNA stability, decay, and transport, to protein translation.

Our $\mathrm{m}^{6} \mathrm{~A}$-seq also found that the viral $\mathrm{G}$ mRNA has the most abundant $\mathrm{m}^{6} \mathrm{~A}$ peaks among the $10 \mathrm{RSV}$ mRNAs in both HeLa and A549 cells. In addition, the strongest $\mathrm{m}^{6} \mathrm{~A}$ peaks in both the genome and the antigenome are located in the $G$ gene region. Another interesting finding was that the positions of the $\mathrm{m}^{6} \mathrm{~A}$ modifications in the genome and antigenome largely overlapped despite the fact that the sequence of the antigenome is complementary to the genome. However, it is unclear why antigenome and genome are $\mathrm{m}^{6} \mathrm{~A}$ methylated because both of them are completely encapsidated by viral $\mathrm{N}$ protein. It was shown that RSV RNA synthesis occurs in cytoplasmic inclusion bodies ${ }^{48}$. In fact, $\mathrm{m}^{6} \mathrm{~A}$-related proteins are partially co-localized with viral $\mathrm{N}$ protein (Fig. 6a, b), suggesting that host $\mathrm{m}^{6} \mathrm{~A}$ machinery may interact with RSV ribonucleoprotein (RNP) complex. It is possible that $\mathrm{m}^{6} \mathrm{~A}$ methylation occurs prior to $\mathrm{N}$ encapsidation, or $\mathrm{m}^{6} \mathrm{~A}$ methylation and encapsidation can occur concurrently.

Since $\mathrm{G}$ mRNA has the strongest $\mathrm{m}^{6} \mathrm{~A}$ enrichment, we searched the three peaks in the $G$ sequence for $\mathrm{m}^{6} \mathrm{~A}$ motifs, identifying a total of 18 putative $\mathrm{m}^{6} \mathrm{~A}$ sites. It is known that the $\mathrm{G}$ gene is the most genetically diverse RSV gene. However, bioinformatics analysis of 100 RSV strains (Supplementary Fig. 17) found that those $18 \mathrm{~m}^{6} \mathrm{~A}$ sites are highly conserved in the $G$ gene, suggesting that $\mathrm{m}^{6} \mathrm{~A}$ sites in the $G$ gene may provide an evolutionary advantage for virus infection, replication, and spreading. Mutations in these three $\mathrm{m}^{6} \mathrm{~A}$ peaks in the $\mathrm{G}$ mRNA showed that peaks 1 and 3 play a major role in regulating RSV replication whereas peak 2 plays a minor role, as recombinant rgRSV mutants in peak 1 and 3 (rgRSV-G1 and G3) had greater deficits in replication compared to mutants in peak 2 (rgRSV-G2).

The $\mathrm{G}$ protein is primarily responsible for the attachment of RSV to host cells and plays a role in modulating innate immune responses ${ }^{47,49}$. Although it is not essential for the production of infectious RSV, RSV G is necessary for full infectivity ${ }^{50,51}$. The G protein also plays an important role in the assembly of filamentous virions ${ }^{52}$. It is likely that the abundant $\mathrm{m}^{6} \mathrm{~A}$ modifications of the $G$ mRNA enhances its stability, enabling more translation, which may lead to insertion of more G protein into virions and enhanced viral assembly and production of infectious virions. However, a portion of the G protein produced in a cell is released in a soluble form that affects leukocyte migration ${ }^{53}$. Enhanced G protein expression could enhance the production of soluble $\mathrm{G}$ protein, thereby affecting the immune response to RSV. It is also possible that $\mathrm{m}^{6} \mathrm{~A}$ modification of viral RNAs facilitate virus escape from the surveillance of host innate immunity to allow for efficient gene expression and virus replication. In this study, we also found that rgRSVs carrying mutations in the $\mathrm{m}^{6} \mathrm{~A}$ sites in $G$ not only decreased $G$ protein expression but also reduced expression of other viral proteins (such as $\mathrm{N}$ and $\mathrm{F}$ proteins). Since RSV replication and transcription require ongoing protein synthesis, a reduction in viral $G$ protein expression will affect the second round of viral infection, which results in a reduction of overall replication and transcription, and expression of all viral proteins.

Importantly, we found that viral $\mathrm{m}^{6} \mathrm{~A}$ also modulates viral replication and pathogenesis in vivo. However, the degree of attenuation in cell culture did not always match that in vivo. For example, rgRSV-G1 and G12 had similar levels of attenuation in immortalized cells (A549 and HeLa cells). In cotton rats, rgRSVG1 replication was 7-fold reduced in the lung and nasal turbinate, respectively, whereas rgRSV-G12 had more than 100-fold reductions. Recombinant rgRSV-G2 was only mildly attenuated in cell culture. This recombinant had similar level of replication in lungs $(P>0.05)$, and only had threefold reduction in nasal turbinates $(P<0.05)$. Therefore, it appears that $\mathrm{m}^{6} \mathrm{~A}$ sites in peaks
1 and 2 contributed synergistically to the highly attenuated phenotype of rgRSV-G12 in vivo. The phenotype of these mutants in HAE culture seems to correlate better with the phenotype in cotton rats than in HeLa and A549 cells. Thus, HAE culture may be better system to predict virus replication in vivo. Also, $\mathrm{m}^{6} \mathrm{~A}$-mutated rgRSVs had significantly less histopathology compared to the parental rgRSV. These results demonstrate that $\mathrm{m}^{6} \mathrm{~A}$ not only modulates the virus life cycle in vitro but also regulates viral replication and pathogenesis in vivo.

Recent studies in vesicular stomatitis virus (VSV) found that codon usage also affected genome replication and mRNA transcription in a minigenome assay ${ }^{54}$. Specifically, purine/pyrimidine content in RNA template modulates the stability of the polymerase complex, which results in alteration of the activity of viral RNA synthesis ${ }^{54}$. In this study, we designed mutations in predicted $\mathrm{m}^{6} \mathrm{~A}$ sites to avoid as much as possible alterations to the predicted mRNA secondary structure and to avoid changes in the efficiency of gene expression of the new codon relative to the original codon. We also confirmed the loss of $\mathrm{m}^{6} \mathrm{~A}$ in the predicted region of the $\mathrm{G}$ mRNA by $\mathrm{m}^{6} \mathrm{~A}$ sequencing and tested the functional consequences of reducing the $\mathrm{m}^{6} \mathrm{~A}$ modifications. Functional loss of $\mathrm{m}^{6} \mathrm{~A}$ modifications was examined by comparing replication of the mutant rgRSV in A549 cells overexpressing or depleted of $\mathrm{m}^{6} \mathrm{~A}$-related proteins. The $\mathrm{m}^{6} \mathrm{~A}$ mutated rgRSVs (G1, G12, and G123) were much less dependent on host $\mathrm{m}^{6} \mathrm{~A}$ enzyme compared to the parental rgRSV, confirming that the attenuated phenotype of $\mathrm{m}^{6} \mathrm{~A}$-mutated rgRSVs is due to the reduction of $\mathrm{m}^{6} \mathrm{~A}$ sites in $\mathrm{G}$ mRNA. Removal of $\mathrm{m}^{6} \mathrm{~A}$ sites in the mRNA also removes them from the antigenome, but not from other viral mRNAs, other locations in the antigenome, or sites in the genome. Therefore, rgRSVs lacking particular $\mathrm{m}^{6} \mathrm{~A}$ peaks in the $\mathrm{G}$ gene would be partially but not fully independent of host $\mathrm{m}^{6} \mathrm{~A}$ enzymes.

A potentially important application of this study is in the rational design of live attenuated RSV vaccine candidates by inhibiting $\mathrm{m}^{6} \mathrm{~A}$ addition to the mRNA and antigenome, or perhaps the viral genome. Currently, there is no FDA-approved vaccine for RSV despite the fact that it was first isolated in 1953. A live attenuated vaccine, similar to the effective vaccines for the related measles and mumps viruses, would seem to be one of the most promising methods for protection from RSV disease. However, it has been a challenge to strike the right balance between attenuation and immunogenicity ${ }^{42}$.

Although mutations in individual $\mathrm{m}^{6} \mathrm{~A}$ peaks in the $\mathrm{G}$ mRNA were not sufficient to achieve complete attenuation of RSV replication in vivo, the combination of $\mathrm{m}^{6} \mathrm{~A}$ mutations in peaks 1 and 2 resulted in a recombinant virus that was sufficiently attenuated both in vitro and in vivo. Importantly, cotton rats vaccinated with rgRSV-G12 had similar neutralizing antibody response levels compared to parental rgRSV and were completely protected from rgRSV challenge. In addition, no enhanced lung damage was observed. Thus, rgRSV-G12 may be a good live attenuated vaccine candidate for RSV. This study demonstrates that inhibition of $\mathrm{m}^{6} \mathrm{~A}$ methylation may be a novel method for rationally designing live attenuated vaccines. These $\mathrm{m}^{6} \mathrm{~A}$-mutated rgRSVs would also provide invaluable tools to understand the roles of $\mathrm{m}^{6} \mathrm{~A}$ modification in the innate immune response. In fact, it has been shown that internal $\mathrm{m}^{6} \mathrm{~A}$ modification of in vitro synthesized RNAs prevents recognition of the RNA by the host pattern recognition receptors TLR3 and RIG-I ${ }^{55}$.

This study also provides a novel approach for enhancing viral titers in cell culture, an important consideration in the production of live attenuated vaccines. Attenuated viruses typically grow to lower titers than wild-type virus. In the case of RSV, a relatively large dose of vaccine candidate is required to induce a protective immune response in humans, making vaccine production 
expensive. One strategy might be to produce live attenuated vaccines in cells overexpressing one or more $\mathrm{m}^{6} \mathrm{~A}$ reader or writer proteins, since overexpression of these host $\mathrm{m}^{6} \mathrm{~A}$ machinery components enhance virus yield at least 10 -fold. Such a boost in the production of a vaccine should greatly enhance its economic feasibility. Unfortunately, this approach would not be useful for $\mathrm{m}^{6} \mathrm{~A}$ mutant attenuated viruses, such as the ones described in this report. It should be useful for viruses attenuated by any other method.

In summary, we mapped the internal $\mathrm{m}^{6} \mathrm{~A}$ modifications in RSV RNAs and showed that $\mathrm{m}^{6} \mathrm{~A}$ enhances RSV replication, gene expression, and virus production. In addition, we provide evidence that $\mathrm{m}^{6} \mathrm{~A}$ upregulates RSV pathogenesis and virulence in vivo. These findings highlight viral $\mathrm{m}^{6} \mathrm{~A}$ machinery as a possible novel target for rational design of live attenuated vaccines, for enhanced production of live attenuated vaccines, and for broad-spectrum antiviral drug discovery.

\section{Method}

Ethics statement. The animal study was conducted in strict accordance with USDA regulations and the recommendations in the Guide for the Care and Use of Laboratory Animals of the National Research Council and was approved by The Ohio State University Institutional Animal Care and Use Committee (IACUC; animal protocol no. 2009A0221). The animals were housed within the University Laboratory Animal Resources (ULAR) facilities of The Ohio State University according to the guidelines of the Institutional Animal Care and Use Committee (IACUC). The animal care facilities at The Ohio State University are AAALAC accredited. Every effort was made to minimize potential distress, pain, or discomfort to the animals throughout all experiments.

Cell lines. HeLa (ATCC CCL-2), A549 (ATCC CCL-185), Vero (ATCC CRLCCL81), and HEp-2 (ATCC CCL-23) cell lines were purchased from the American Type Culture Collection (Manassas, VA) and were grown in Dulbecco's modified Eagle's medium (DMEM; Life Technologies) supplemented with 10\% FBS. HeLa cells overexpressing the empty vector (pPB-CAG), YTHDF1, YTHDF2, or YTHDF3 were maintained in DMEM, 10\% FBS and $1 \mu \mathrm{g} / \mathrm{ml}$ of puromycin every passage to select for YTHDF1-3 overexpressing cells. Primary, well-differentiated human airway epithelial (HAE) cultures were grown on collagen coated Transwell inserts (Corning Incorporated, Corning, NY) at an air-liquid interface, as previously described ${ }^{47}$. Upon reaching confluency and forming tight junctions, the apical medium was removed and cultures were maintained at the air-liquid interface for 4-6 weeks to generate well-differentiated, polarized cultures. All cell lines used in this study were free of mycoplasma, as confirmed by the LookOut Mycoplasma PCR Detection Kit (Sigma).

Virus stocks and purification. Recombinant RSV containing a green fluorescence protein $(G F P)$ gene between the leader sequence and NS1 gene $(\mathrm{rgRSV})^{47}$ was propagated and titered in HeLa cells or A549 cells. To prepare purified rgRSV, 20 T150 flasks of HeLa cells or A549 cells were infected by roRSV at an MOI of 0.1 , and cell culture supernatants harvested at 48 or $72 \mathrm{~h}$ post-infection were clarified by centrifugation at $10,000 \times g$ for $30 \mathrm{~min}$. Virus was concentrated through a $35 \%$ (wt/vol) sucrose cushion by centrifugation at $30,000 \times g$ for $2 \mathrm{~h}$ at $4{ }^{\circ} \mathrm{C}$ in a Ty 50.2 rotor (Beckman). The pellet was resuspended in DMEM with 10\% trehalose and further purified through a sucrose gradient $(20-55 \%)$ by centrifugation at $35,000 \times g$ for $2 \mathrm{~h}$ at $4{ }^{\circ} \mathrm{C}$ in an SW55 rotor (Beckman). The final pellet was resuspended in $0.5 \mathrm{ml}$ of DMEM with $10 \%$ trehalose.

$\mathbf{m}^{6} \mathbf{A}$-seq. High-throughput sequencing of the RSV and host methylome was carried out using $\mathrm{m}^{6} \mathrm{~A}$-seq (MeRIP-seq) as described previously ${ }^{20}$. For $\mathrm{m}^{6} \mathrm{~A}$-seq of the rgRSV genome and antigenome, RNAs were extracted from purified rgRSV virions and purified with the RiboMinus Eukaryote System v2 kit (Thermo Fisher). For $\mathrm{m}^{6} \mathrm{~A}$-seq of host transcripts, total RNAs were extracted from mock or rgRSVinfected HeLa or A549 cells and polyadenylated RNAs were isolated using Dynabeads mRNA DIRECT Purification kit (Thermo Fisher). Purified RNAs were sonicated with Bioruptor Pico (Diagenode) with 30s ON 30s OFF for 30 cycles, mixed with $1 \mu \mathrm{l}$ of affinity purified anti- $\mathrm{m}^{6} \mathrm{~A}$ monoclonal antibody (NEB) in IPP buffer ( $150 \mathrm{mM} \mathrm{NaCl}, 0.1 \% \mathrm{NP}-40,10 \mathrm{mM}$ Tris-HCl, $\mathrm{pH} 7.4)$ and incubated for $2 \mathrm{~h}$ at $4^{\circ} \mathrm{C}$. Enriched mRNA fragments were purified with RNA Clean \& Concentrator kit (Zymo) and used for library generation with TruSeq Stranded mRNA Library Prep kit (Illumina). Sequencing was carried out on Illumina HiSeq 4000 according to the manufacturer's instructions. Two replicates of RNA samples from virions, virus-infected cells, and mock-infected cells were subjected to $\mathrm{m}^{6} \mathrm{~A}$-seq. For data analysis, after removing the adapter sequences, the reads were mapped to the human genome (hg38) and rgRSV genome and antigenome by using Hisat $2^{56}$ with peak calling as described ${ }^{57}$. Metagene analysis was performed by R package
Guitar ${ }^{58}$. Differential methylation analysis was performed with count based negative binomial model implemented in QNB test ${ }^{46}$.

Quantification of RSV RNA $\mathbf{m}^{\mathbf{6}} \mathbf{A}$ level using LC-MS/MS. RSV RNA (250 mg) was extracted from highly purified rgRSV virions using an RNeasy Mini kit (Qiagen) and purified twice with RiboMinus Eukaryote System v2 kit (Thermo Fisher). To examine the purity of virion RNA, oligo $d(T)$ was used for reverse transcription, followed by qPCR for quantification for $\beta$-actin and viral N and G mRNAs. Virion RNA which was free of contamination of host RNA and viral mRNAs was used for liquid chromatography-mass spectrometry (LC-MS/MS), $\mathrm{m}^{6} \mathrm{~A}$ antibody pulldown assay, and $\mathrm{m}^{6} \mathrm{~A}$-seq. Purified RNA was digested and subjected to a quantitative analysis of the $\mathrm{m}^{6} \mathrm{~A}$ level using LC-MS/MS as previously described $^{7}$.

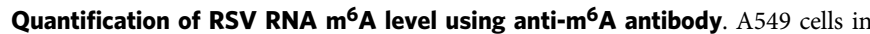
T150 flasks were transfected with $10 \mu \mathrm{g}$ of plasmids encoding METTL3 and METTL14, ALKBH5, or vector pCAGGS. For siRNA transfection, A549 cells in T75 flasks were transfected with 150 pmole of siRNA targeting METTL3 and METTL14, ALKBH5, or control siRNA. At $24 \mathrm{~h}$ post-transfection, the transfected cells were infected with rgRSV at an MOI of 0.1 . At $42 \mathrm{~h}$ post-infection, cell culture supernatants (containing RSV particles) were harvested. RSV particles were pelleted and purified through ultracentrifugation. Virion RNA was extracted from highly purified RSV virions. Antigenome was quantified by real-time RT-PCR. Each amount of antigenome was bound to strip wells using a RNA high binding solution, and $\mathrm{m}^{6} \mathrm{~A}$ was detected using a specific capture anti- $\mathrm{m}^{6} \mathrm{~A}$ antibody (Abcam, ab185912) and then quantified colorimetrically by reading the absorbance in a microplate spectrophotometer at a wavelength of $450 \mathrm{~nm}$. A standard curve was generated using known $\mathrm{m}^{6} \mathrm{~A}$ methylated RNA (range from 0.02 to $1 \mathrm{ng}$ of $\mathrm{m}^{6} \mathrm{~A}$ ) as a positive control. The $\mathrm{m}^{6} \mathrm{~A}$ content was calculated from each RNA samples based on their OD450 values. The percent of changes was calculated by dividing $\mathrm{m}^{6} \mathrm{~A}$ contents in viral RNA from the treated group by those from the control group.

Host cell gene differential expression analysis. Host cell differential gene expression was analyzed by R package DESeq ${ }^{58}$ using wald-test. The significantly differentially expressed genes were reported at adjusted $P$ value cutoff of 0.05 .

GO analysis. Gene Ontogeny (GO) analysis was performed using the R package cluster Profiler ${ }^{58}$. Specifically, enrichKEGG function was called to analyze for enriched pathway and enrichMap function was called to generate network plot of enriched pathway.

Plasmids and site-directed mutagenesis. The plasmid vector was used to overexpress the readers (YTHDF1-3), writers (METTL3, METTL14), and erasers (FTO, ALKBH5) as described previously ${ }^{32}$. Plasmid (RW30) encoding the fulllength antigenomic cDNA of RSV strain A2 with GFP inserted between the leader and the NS1 gene, and support plasmids expressing RSV A2 strain N protein (pTM1-N), P protein (pTM1-P), L protein (pTM1-L), and M2-1 protein (pTM1M2-1) were generously provided by Dr. P.L. Collins, NIAID, Bethesda, MD. Mutations to the potential $\mathrm{m}^{6} \mathrm{~A}$ sites in $\mathrm{G}$ gene were introduced into the RW30 plasmids using QuikChange site-directed mutagenesis kit (Stratagene, La Jolla, CA). The $\mathrm{m}^{6} \mathrm{~A}$ peaks in the $\mathrm{G}$ gene are clustered in three regions, $392-467 \mathrm{nt}$, 567-660 nt, and 716-795 nt. Since it is known that $\mathrm{m}^{6} \mathrm{~A}$ modified sites in RNA contain the conserved $\mathrm{Pu}[\mathrm{G}>\mathrm{A}] \mathrm{m}^{6} \mathrm{AC}[\mathrm{A} / \mathrm{C} / \mathrm{U}]$ motif (Pu represents purine) $)^{1}$, we searched for this motif in these three regions in G mRNA and identified 6, 7, and 4 potential $\mathrm{m}^{6} \mathrm{~A}$ sites in regions G1, G2, and G3 respectively (Supplementary Fig. 13) The potential $\mathrm{m}^{6} \mathrm{~A}$ sites mutants in G1 peak include 394-AGm ${ }^{6} \mathrm{ACC}-400$; 401 AAm ${ }^{6}$ ACA-407; 418-AAm ${ }^{6}$ ACA-424; 444-AAm ${ }^{6}$ ACA-450; $455-$ Am $^{6}$ ACA-461; 459-AA ${ }^{6}$ ACC-465; mutants in G2 peak include 569 -AAm ${ }^{6} \mathrm{ACA}-5 \overline{75}$; 576 AAm ${ }^{6}$ A $\overline{C C}-582 ; 589-A A m^{6}$ ACC-595; 612-AAm ${ }^{6}$ ACC-618; 625-AGm ${ }^{6}$ ACA-631; 645-AA ${ }^{6}$ ACC-651; $652-$ AA $^{6}$ ACC-658; and mutants in G3 peak include 718 AAm ${ }^{6} \mathrm{ACA}-724 ; 722-A m^{6}{ }^{A} \overline{C A}-728 ; 768-G A m^{6}$ ACT-774; 787-AAm ${ }^{6}$ ACC-793 (Supplementary Fig. 13). The $\mathrm{A}$ or $\mathrm{C}$ within the consensus $\mathrm{m}^{6} \mathrm{~A}$ sites was mutated to a $\mathrm{T}$ or $\mathrm{G}$ in these sites without changing the encoded amino acid. Mutant G12 combined the mutations from G1 and G2. Mutant G123 was a combined the mutations from G1, G2, and G3. In addition, M-fold and Genscript software were used to predict that these mutations did not alter RNA secondary structure or codon usage. All plasmids and mutations were confirmed by DNA sequencing.

siRNA and siRNA transfection. siRNAs against METTL3, METTL14, FTO, ALKBH5, YTHDF1, YTHDF2, YTHDF3, or non-targeting AllStars negative control siRNA were purchased from Qiagen (Valencia, CA, sequences listed in Supplementary Table 7). All siRNA transfections were performed using the Lipofectamine 3000 transfection reagent (Thermo-Fisher) according to the manufacturer's instructions.

Antibodies and Western blotting. The antibodies used in this study were antiYTHDF1 (1:1000, Proteintech, Rosemont, IL), anti-YTHDF2 (1:1000, Abcam, 
Cambridge, MA), anti-YTHDF3 (1:1000, Abcam), anti-METTL3 (1:1000, Proteintech), anti-METTL14 (1:1000, Proteintech), anti-ALKBH5 (1:1000, SigmaAldrich, St. Louis, MO), anti-FTO (1:1000, Abcam), and anti-RSV serum (1:400, Virostat, Westbrook, ME), F (1:3000, Abcam), anti-FLAG (1:3000, Sigma-Aldrich), anti-Actin (1:5000, Proteintech), and anti-Tubulin (1:5000, Abcam). Cells were harvested and lysed in RIPA buffer (Abcam) supplemented with protease inhibitor cocktail (Sigma-Aldrich). Western blotting was performed as described. Tubulin or actin was used as a loading control.

\section{Immunofluorescence analysis and confocal microscopy. Mock or rgRSV-} infected cells were fixed in acetone and methanol at the ratio of 1:1 for $30 \mathrm{~min}$, and blocked with $10 \%$ goat serum. Slides were stained with all primary antibodies (1:100), washed three times with PBST, and stained with conjugated Alexa Fluor secondary antibodies Alexa Fluor 488/594 (1:300, Thermo-Fisher), and mounted with SlowFade ${ }^{\mathrm{m}}$ Diamond Antifade Mountant with DAPI (Thermo-Fisher). Imaging was performed on an Olympus FV 1000 confocal microscopy system at The Ohio State University Campus Microscopy \& Imaging Facility.

Real-time RT-PCR. RSV genome, antigenome, and mRNA were quantified by realtime RT-PCR. HeLa or A549 cells were infected with rgRSV or an rgRSV mutant at an MOI of 0.1. At 12, 18, and 24 post-infection, total RNA was isolated from cells using TRIzol (Life Technologies). Viral genome or antigenome copies were quantified by real-time RT-PCR using two primers specifically targeting the RSV leader sequence and GFP gene (Supplementary Table 8). Poly (A)-containing viral mRNAs were isolated from total RNA using a Dynabead mRNA isolation kit (Life Technologies) according to the manufacturer's recommendations. Using the viral mRNAs as the template, the NS1 and G mRNA copies were quantified by real-time RT-PCR using two primers targeting the viral NS1 and G genes, respectively.

RNA-immunoprecipitation. The RNA-immunoprecipitation (RIP) assay was performed as described previously ${ }^{38}$. In brief, HeLa cells were infected with rgRSV at MOI of 1.0 and cell extracts were harvested in polysome lysis buffer after $36 \mathrm{~h}$ post-infection. RNP complexes were immunoprecipitated with anti-HA antibody conjugated to magnetic beads (Sigma) or anti-YTHDF2 antibody overnight at $4{ }^{\circ} \mathrm{C}$, and washed five times with ice-cold NT2 buffer. For the RIP with anti-YTHDF2 antibody, additional secondary antibody was added. After the final wash, $10 \%$ of the beads were used for immunoblotting and the remaining $90 \%$ were used for RNA extraction using TRIzol (ThermoFisher).

Recovery of RSV from the full-length cDNA clones. rgRSV mutants were rescued from the full-length cDNA of the RSV A2 strain ${ }^{59}$. HEp-2 cells were infected with MVA-T7 at an MOI of 10, then transfected with $1.2 \mu \mathrm{g}$ of plasmid RW30 or RW30 mutant, $0.4 \mu \mathrm{g}$ of pTM1-N, $0.2 \mu \mathrm{g}$ of pTM1-P, $0.1 \mu \mathrm{g}$ of pTM1-M2-1, and $0.1 \mu \mathrm{g}$ of pTM1-L using the Lipofectamine 3000 reagent (Life Technologies). At day 4 post-transfection, the cells were harvested using scrapers and were co-cultured with new flask of HEp-2 cells at 50-60\% confluence. When an extensive cytopathic effect (CPE) was observed, the cells were subjected to three freeze-thaw cycles, followed by centrifugation at $4000 \times g$ for $10 \mathrm{~min}$. The supernatant was subsequently used to infect new HEp-2 cells. The successful recovery of the rgRSV was confirmed by the presence of green fluorescent cells, followed by RT-PCR and sequencing. Recombinants rgRSV carrying mutations in $\mathrm{m}^{6} \mathrm{~A}$ sites were designated as rgRSV-G1, G2, G3, G12, and G123.

RT-PCR and sequencing. All plasmids, viral mutants and stocks, and virus isolates from the nasal turbinates and lungs of cotton rats were sequenced to confirm virus identity. Viral RNA was extracted from $100 \mu \mathrm{l}$ of each recombinant virus using an RNeasy minikit (Qiagen, Valencia, CA). A 1.5-kb DNA fragment spanning the RSV $G$ gene was amplified by RT-PCR. The PCR products were purified and sequenced using a sequencing primer at The Ohio State University Plant Microbe Genetics Facility to confirm the presence of the designed mutations.

Viral replication kinetics. Confluent HeLa or A549 cells in 6-well-plate were infected with wild-type rgRSV or mutant rgRSV at an MOI of 0.1 . After $1 \mathrm{~h}$ of adsorption, the inoculum was removed and the cells were washed three times with DMEM. Fresh DMEM (supplemented with 2\% FBS) was added, and the infected cells were incubated at $37^{\circ} \mathrm{C}$. At different time points post-inoculation, the supernatant and cells were harvested by three freeze-thaw cycles, followed by centrifugation at $1500 \times g$ at room temperature for $15 \mathrm{~min}$. The virus titer was determined by TCID 50 assay in HEp-2 cells ${ }^{47}$.

Genetic stability of rgRSV mutants in cell culture. Confluent Vero cells in T25 flasks were infected with each rgRSV mutant at an MOI of 0.1 . At day 3 postinoculation, the cell culture supernatant was harvested and used for the next passage in Vero cells. Using this method, each rgRSV mutant was repeatedly passaged 15 times in Vero cells. At each passage, the $G$ gene was amplified by RTPCR and sequenced. At passage 15, the entire genome of each recombinant virus was amplified by RT-PCR and sequenced.
Replication and pathogenesis of rgRSV in cotton rats. Thirty 6-week-old specific-pathogen-free (SPF) male cotton rats (Envigo, Indianapolis, IN) were randomly divided into 6 groups ( 5 cotton rats per group). Prior to virus inoculation, the cotton rats were anesthetized with isoflurane. The cotton rats in group 1 were inoculated with $2.0 \times 10^{5} \mathrm{TCID}_{50}$ of parental rgRSV and served as positive controls The cotton rats in groups 2-5 were inoculated with $2.0 \times 10^{5} \mathrm{TCID}_{50}$ of four $\mathrm{m}^{6} \mathrm{~A}$ deficient rgRSV mutants, rgRSV-G1, G2, G3, and G12. Each cotton rat was inoculated intranasally with a volume of $100 \mu$ l. At day 4 post-infection, the cotton rats were killed via carbon dioxide inhalation. The left lung and nasal turbinates were collected for virus titration and the right lung was collected for histological analysis.

Immunogenicity of rgRSV in cotton rats. For the immunogenicity study, twenty 6-week-old female cotton rats (Envigo) were randomly divided into five groups (5 cotton rats per group). Cotton rats in groups 1,2 , and 3 were intranasally inoculated with $2.0 \times 10^{5} \mathrm{TCID}_{50}$ of two $\mathrm{m}^{6} \mathrm{~A}$ deficient rgRSV mutants (rgRSV-G1 and G12) and rgRSV, respectively. Cotton rats in groups 4 were mock-infected with DMEM and served as unvaccinated challenged control. After immunization, the cotton rats were evaluated daily for any possible abnormal reaction and blood samples were collected from each cotton rat weekly by facial vein retro-orbital plexus sampling, and serum was used for detection of neutralizing antibodies. At 4 weeks post-immunization, the cotton rats in groups $2-5$ were challenged with $2.0 \times 10^{5} \mathrm{TCID}_{50}$ of parental rgRSV via intranasal route, and evaluated twice daily for the presence of any clinical symptoms. At 4 days post-challenge, all cotton rats were euthanized by $\mathrm{CO}_{2}$ asphyxiation, and their lungs and nasal turbinates were collected for virus titration. The immunogenicity of rgRSV mutants was assessed based on their ability to trigger neutralizing antibody, the ability to prevent rgRSV replication in lungs and nose, and the ability to protect lung from pathological changes.

Pulmonary histology. After killing, the right lung of each animal was removed, inflated, and fixed with $4 \%$ neutral buffered formaldehyde. Fixed tissues were embedded in paraffin and a microtome used to generate $5 \mu \mathrm{m}$ sections. Slides were then stained with hematoxylin-eosin (H\&E) for the examination of histological changes by light microscopy. Histopathological changes were evaluated based on the extent of interstitial inflammation, edema, and peribronchiolar inflammation.

Determination of viral titer in lung and nasal turbinate. The nasal turbinate and the left lung from each cotton rat were removed, weighed, and homogenized in either $3 \mathrm{ml}$ or $2 \mathrm{ml}$ of DMEM. The lung was homogenized using a Precellys 24 tissue homogenizer (Bertin, MD) by following the manufacturer's recommendations. The nasal turbinates were homogenized by hand with a $15-\mathrm{mL}$ capacity PYREX $^{\circledast}$ homogenizer (Corning, NY). The presence of infectious virus was determined by TCID $_{50}$ assay in HEp-2 cells.

Determination of RSV-neutralizing antibody. RSV-specific neutralizing antibody titers were determined using a plaque reduction neutralization assay. In brief, cotton rat sera were collected by retro-orbital plexus sampling weekly until challenge. The serum samples were heat inactivated at $56^{\circ} \mathrm{C}$ for $30 \mathrm{~min}$. Twofold dilutions of the serum samples were mixed with an equal volume of DMEM containing $\sim 50 \mathrm{TCID}_{50} /$ well $\mathrm{rgRSV}$ in a 96-well plate, and the plate was incubated at room temperature for $1 \mathrm{~h}$ with constant rotation. The mixtures were then transferred to confluent HEp-2 cells in a 96-well plate in triplicate. After $1 \mathrm{~h}$ of incubation at $37^{\circ} \mathrm{C}$, the virus-serum mixtures were removed and the cells were overlaid with $0.75 \%$ methylcellulose in overlay media $(1 \times$ MEM, $2 \%$ FBS, Sodium bicarbonate, $25 \mathrm{mM}$ HEPES, $1 \%$ L-Glutamine, $1 \%$ Pen Strep) and incubated for another 3 days before counting the fluorescent foci. The numbers of foci at each serum dilution were plotted and the $50 \%$ plaque reduction titer was used as the RSV-specific neutralizing antibody titer.

Statistical analysis. Quantitative analysis was performed by either densitometric scanning of autoradiographs or by using a phosphorimager (Typhoon; GE Healthcare, Piscataway, NJ), ImageQuant TL software (GE Healthcare, Piscataway, $\mathrm{NJ}$ ), and Image J (NIH, Bethesda, MD). Statistical analysis was performed by oneway multiple comparisons using SPSS (version 8.0) statistical analysis software (SPSS Inc., Chicago, IL) or Student's $t$-test. A $P$ value of $<0.05$ was considered statistically significant.

Reporting summary. Further information on research design is available in the Nature Research Reporting Summary linked to this article.

\section{Data availability}

The authors declare that the data supporting the findings of this study are available with the article and its Supplementary Information files, or are available from the corresponding author upon request. The accession number for the raw sequencing data obtained from the MeRIP-seq reported in this paper is GEO: GSE125803 [https://www. ncbi.nlm.nih.gov/geo/query/acc.cgi]. The source data underlying Figures and Supplementary Figures are provided as a Source Data file. 
Received: 20 August 2018; Accepted: 11 September 2019;

Published online: 09 October 2019

\section{References}

1. Yue, Y., Liu, J. \& He, C. RNA N6-methyladenosine methylation in posttranscriptional gene expression regulation. Genes Dev. 29, 1343-1355 (2015).

2. Roundtree, I. A., Evans, M. E., Pan, T. \& He, C. Dynamic RNA modifications in gene expression regulation. Cell 169, 1187-1200 (2017).

3. Desrosiers, R., Friderici, K. \& Rottman, F. Identification of methylated nucleosides in messenger RNA from Novikoff hepatoma cells. Proc. Natl Acad. Sci. USA 71, 3971-3975 (1974).

4. Lavi, S. \& Shatkin, A. J. Methylated simian virus 40-specific RNA from nuclei and cytoplasm of infected BSC-1 cells. Proc. Natl Acad. Sci. USA 72, 2012-2016 (1975).

5. Perry, R. P., Kelley, D. E., Friderici, K. \& Rottman, F. The methylated constituents of L cell messenger RNA: evidence for an unusual cluster at the 5' terminus. Cell 4, 387-394 (1975).

6. Wei, C. M., Gershowitz, A. \& Moss, B. Methylated nucleotides block 5' terminus of HeLa cell messenger RNA. Cell 4, 379-386 (1975).

7. Jia, G. et al. N6-methyladenosine in nuclear RNA is a major substrate of the obesity-associated FTO. Nat. Chem. Biol. 7, 885-887 (2011).

8. Zheng, G. et al. ALKBH5 is a mammalian RNA demethylase that impacts RNA metabolism and mouse fertility. Mol. Cell 49, 18-29 (2013).

9. Darnell, R. B., Ke, S. \& Darnell, J. E. Jr. Pre-mRNA processing includes N(6) methylation of adenosine residues that are retained in mRNA exons and the fallacy of "RNA epigenetics". RNA 24, 262-267 (2018).

10. Meyer, K. D. et al. Comprehensive analysis of mRNA methylation reveals enrichment in 3' UTRs and near stop codons. Cell 149, 1635-1646 (2012).

11. Linder, B. et al. Single-nucleotide-resolution mapping of m6A and m6Am throughout the transcriptome. Nat. Methods 12, 767-772 (2015).

12. Dominissini, D., Moshitch-Moshkovitz, S., Salmon-Divon, M., Amariglio, N. \& Rechavi, G. Transcriptome-wide mapping of N(6)-methyladenosine by $\mathrm{m}$ (6)A-seq based on immunocapturing and massively parallel sequencing. Nat. Protoc. 8, 176-189 (2013).

13. Meyer, K. D. \& Jaffrey, S. R. The dynamic epitranscriptome: N6methyladenosine and gene expression control. Nat. Rev. Mol. Cell Biol. 15, 313-326 (2014).

14. $\mathrm{Vu}, \mathrm{L}$. P. et al. The N6-methyladenosine (m6A)-forming enzyme METTL3 controls myeloid differentiation of normal hematopoietic and leukemia cells. Nat. Med. 23, 1369-1376 (2017).

15. Jaffrey, S. R. \& Kharas, M. G. Emerging links between $\mathrm{m} 6 \mathrm{~A}$ and misregulated mRNA methylation in cancer. Genome Med. 9, 2 (2017).

16. Wang, X. et al. N(6)-methyladenosine modulates messenger RNA translation efficiency. Cell 161, 1388-1399 (2015).

17. Zhao, B. S. et al. m6A-dependent maternal mRNA clearance facilitates zebrafish maternal-to-zygotic transition. Nature 542, 475-478 (2017).

18. Liu, J. et al. A METTL3-METTL14 complex mediates mammalian nuclear RNA N6-adenosine methylation. Nat. Chem. Biol. 10, 93-95 (2014).

19. Ping, X. L. et al. Mammalian WTAP is a regulatory subunit of the RNA N6methyladenosine methyltransferase. Cell Res. 24, 177-189 (2014).

20. Dominissini, D. et al. Topology of the human and mouse m6A RNA methylomes revealed by m6A-seq. Nature 485, 201-206 (2012).

21. Wang, X. et al. N6-methyladenosine-dependent regulation of messenger RNA stability. Nature 505, 117-120 (2014).

22. Shi, H. et al. YTHDF3 facilitates translation and decay of N6methyladenosine-modified RNA. Cell Res. 27, 315-328 (2017).

23. $\mathrm{Li}, \mathrm{A}$. et al. Cytoplasmic m6A reader YTHDF3 promotes mRNA translation. Cell Res. 27, 444-447 (2017).

24. Kane, S. E. \& Beemon, K. Precise localization of m6A in Rous sarcoma virus RNA reveals clustering of methylation sites: implications for RNA processing. Mol. Cell Biol. 5, 2298-2306 (1985).

25. Canaani, D., Kahana, C., Lavi, S. \& Groner, Y. Identification and mapping of N6-methyladenosine containing sequences in simian virus 40 RNA. Nucleic Acids Res. 6, 2879-2899 (1979).

26. Sommer, S. et al. The methylation of adenovirus-specific nuclear and cytoplasmic RNA. Nucleic Acids Res. 3, 749-765 (1976).

27. Moss, B., Gershowitz, A., Stringer, J. R., Holland, L. E. \& Wagner, E. K. 5'Terminal and internal methylated nucleosides in herpes simplex virus type 1 mRNA. J. Virol. 23, 234-239 (1977).

28. Furuichi, Y., Shatkin, A. J., Stavnezer, E. \& Bishop, J. M. Blocked, methylated 5'-terminal sequence in avian sarcoma virus RNA. Nature 257, 618-620 (1975).

29. Krug, R. M., Morgan, M. A. \& Shatkin, A. J. Influenza viral mRNA contains internal N6-methyladenosine and 5'-terminal 7-methylguanosine in cap structures. J. Virol. 20, 45-53 (1976).
30. Kennedy, E. M. et al. Posttranscriptional m(6)A editing of HIV-1 mRNAs enhances viral gene expression. Cell Host Microbe 19, 675-685 (2016).

31. Lichinchi, G. et al. Dynamics of the human and viral m(6)A RNA methylomes during HIV-1 infection of T cells. Nat. Microbiol. 1, 16011 (2016).

32. Tirumuru, N. et al. N(6)-methyladenosine of HIV-1 RNA regulates viral infection and HIV-1 Gag protein expression. eLife 5, e15528 (2016).

33. Courtney, D. G. et al. Epitranscriptomic enhancement of influenza A virus gene expression and replication. Cell Host Microbe 22, 377-386 e375 (2017).

34. Tsai, K., Courtney, D. G. \& Cullen, B. R. Addition of m6A to SV40 late mRNAs enhances viral structural gene expression and replication. PLoS Pathog. 14, e1006919 (2018).

35. Hesser, C. R., Karijolich, J., Dominissini, D., He, C. \& Glaunsinger, B. A. N6methyladenosine modification and the YTHDF2 reader protein play cell type specific roles in lytic viral gene expression during Kaposi's sarcoma-associated herpesvirus infection. PLoS Pathog. 14, e1006995 (2018).

36. Ye, F., Chen, E. R. \& Nilsen, T. W. Kaposi's sarcoma-associated herpesvirus utilizes and manipulates RNA N(6)-adenosine methylation to promote lytic replication. J. Virol. 91, e00466-17 (2017).

37. Tan, B. et al. Viral and cellular N(6)-methyladenosine and N(6),2'-Odimethyladenosine epitranscriptomes in the KSHV life cycle. Nat. Microbiol. 3, 108-120 (2018)

38. Gokhale, N. S. et al. N6-methyladenosine in flaviviridae viral RNA genomes regulates infection. Cell Host Microbe 20, 654-665 (2016).

39. Fearns, R., Peeples, M. E. \& Collins, P. L. Increased expression of the N protein of respiratory syncytial virus stimulates minigenome replication but does not alter the balance between the synthesis of mRNA and antigenome. Virology 236, 188-201 (1997).

40. Ruigrok, R. W., Crepin, T. \& Kolakofsky, D. Nucleoproteins and nucleocapsids of negative-strand RNA viruses. Curr. Opin. Microbiol. 14, 504-510 (2011).

41. Afonso, C. L. et al. Taxonomy of the order Mononegavirales: update 2016. Arch. Virol. 161, 2351-2360 (2016).

42. Collins, P. L. \& Graham, B. S. Viral and host factors in human respiratory syncytial virus pathogenesis. J. Virol. 82, 2040-2055 (2008).

43. Nair, H. et al. Global burden of acute lower respiratory infections due to respiratory syncytial virus in young children: a systematic review and metaanalysis. Lancet 375, 1545-1555 (2010).

44. Cowton, V. M., McGivern, D. R. \& Fearns, R. Unravelling the complexities of respiratory syncytial virus RNA synthesis. J. Gen. Virol. 87, 1805-1821 (2006).

45. Kolakofsky, D. \& Bruschi, A. Antigenomes in Sendai virions and Sendai virusinfected cells. Virology 66, 185-191 (1975).

46. Liu, L., Zhang, S. W., Huang, Y. \& Meng, J. QNB: differential RNA methylation analysis for count-based small-sample sequencing data with a quad-negative binomial model. BMC Bioinform. 18, 387 (2017).

47. Johnson, S. M. et al. Respiratory syncytial virus uses CX3CR1 as a receptor on primary human airway epithelial cultures. PLoS Pathog. 11, e1005318 (2015)

48. Rincheval, V. et al. Functional organization of cytoplasmic inclusion bodies in cells infected by respiratory syncytial virus. Nat. Commun. 8, 563 (2017).

49. Boyoglu-Barnum, S. et al. Mutating the CX3C motif in the $\mathrm{G}$ protein should make a live respiratory syncytial virus vaccine safer and more effective. $J$. Virol. 91, e02059-16 (2017).

50. Teng, M. N. \& Collins, P. L. The central conserved cystine noose of the attachment $G$ protein of human respiratory syncytial virus is not required for efficient viral infection in vitro or in vivo. J. Virol. 76, 6164-6171 (2002).

51. Teng, M. N., Whitehead, S. S. \& Collins, P. L. Contribution of the respiratory syncytial virus $\mathrm{G}$ glycoprotein and its secreted and membrane-bound forms to virus replication in vitro and in vivo. Virology 289, 283-296 (2001).

52. Vanover, D. et al. RSV glycoprotein and genomic RNA dynamics reveal filament assembly prior to the plasma membrane. Nat. Commun. 8, 667 (2017)

53. Tripp, R. A. et al. CX3C chemokine mimicry by respiratory syncytial virus $\mathrm{G}$ glycoprotein. Nat. Immunol. 2, 732-738 (2001).

54. Gumpper, R. H., Li, W. \& Luo, M. Constraints of Viral RNA Synthesis on Codon Usage of Negative-Strand RNA Virus. J. Virol. 93, e01775-18 (2019).

55. Durbin, A. F., Wang, C., Marcotrigiano, J. \& Gehrke, L. RNAs containing modified nucleotides fail to trigger RIG-I conformational changes for innate immune signaling. mBio 7, e00833-16 (2016).

56. Kim, D., Langmead, B. \& Salzberg, S. L. HISAT: a fast spliced aligner with low memory requirements. Nat. Methods 12, 357-360 (2015).

57. Ma, L. et al. Evolution of transcript modification by N6-methyladenosine in primates. Genome Res. 27, 385-392 (2017).

58. Cui, X. et al. Guitar: an R/Bioconductor Package for gene annotation guided transcriptomic analysis of RNA-related genomic features. BioMed. Res. Int. 2016, 8367534 (2016)

59. Collins, P. L. et al. Production of infectious human respiratory syncytial virus from cloned cDNA confirms an essential role for the transcription elongation factor from the 5' proximal open reading frame of the M2 mRNA in gene expression and provides a capability for vaccine development. Proc. Natl Acad. Sci. USA 92, 11563-11567 (1995). 


\section{Acknowledgements}

This study was supported by NIH grant R01 AI090060 to J.L., and P01 AI112524 to M.E.P., S.N., and J.L., and R01 HG008688 and RM1 HG008935 to C.H. We thank Peter Collins for the infectious cDNA clone of RSV. We are grateful to members of the J. Li laboratory for critically reading the manuscript.

\section{Author contributions}

M.X., C.H., and J.L. conceived the study. M.X., B.Z., Z.Z., M.L., O.H., P.C., Z.L., A.L., Y.M., Y.X., X.L., J.Z., S.N., M.E.P., C.H., and J. L. performed experiments and data analysis. M.X., B.Z., Z.Z., J.Z., S.N., M.E.P., C.H., and J.L. designed the experiments and interpreted the results. M.X., B.Z., Z.Z., M.E.P., C.H., and J.L. wrote the manuscript, and all other authors edited the manuscript.

\section{Competing interests}

The authors declare no competing interests.

\section{Additional information}

Supplementary information is available for this paper at https://doi.org/10.1038/s41467019-12504-y.

Correspondence and requests for materials should be addressed to J.L.

Peer review information Nature Communications thanks the anonymous reviewers for their contribution to the peer review of this work.
Reprints and permission information is available at http://www.nature.com/reprints

Publisher's note Springer Nature remains neutral with regard to jurisdictional claims in published maps and institutional affiliations.

(c) Open Access This article is licensed under a Creative Commons Attribution 4.0 International License, which permits use, sharing, adaptation, distribution and reproduction in any medium or format, as long as you give appropriate credit to the original author(s) and the source, provide a link to the Creative Commons license, and indicate if changes were made. The images or other third party material in this article are included in the article's Creative Commons license, unless indicated otherwise in a credit line to the material. If material is not included in the article's Creative Commons license and your intended use is not permitted by statutory regulation or exceeds the permitted use, you will need to obtain permission directly from the copyright holder. To view a copy of this license, visit http://creativecommons.org/ licenses/by/4.0/.

(C) The Author(s) 2019 